\title{
Genome-wide mapping of 10 calving and fertility traits in Holstein dairy cattle with special regard to chromosome 18
}

\author{
M.-P. Müller, ${ }^{*} \dagger$ S. Rothammer, $\dagger$ D. Seichter, ${ }^{*}$ I. Russ, ${ }^{*}$ D. Hinrichs,$\ddagger^{1}$ J. Tetens, $\ddagger^{2}$ G. Thaller, ${ }^{*} \ddagger$ \\ and I. Medugoract ${ }^{3}$ \\ *Tierzuchtforschung e.V. München, Senator-Gerauer-Str. 23, 85586 Poing, Germany \\ †Chair of Animal Genetics and Husbandry, Ludwig-Maximilians-Universität Munich, Veterinärstr. 13, 80539 Munich, Germany \\ łInstitute of Animal Breeding and Husbandry, Christian-Albrechts-University, Olshausenstr. 40, 24098 Kiel, Germany
}

\begin{abstract}
Over the last decades, a dramatic decrease in reproductive performance has been observed in Holstein cattle and fertility problems have become the most common reason for a cow to leave the herd. The premature removal of animals with high breeding values results in both economic and breeding losses. For efficient future Holstein breeding, the identification of loci associated with low fertility is of major interest and thus constitutes the aim of this study. To reach this aim, a genome-wide combined linkage disequilibrium and linkage analysis (cLDLA) was conducted using data on the following 10 calving and fertility traits in the form of estimated breeding values: days from first service to conception of heifers and cows, nonreturn rate on d 56 of heifers and cows, days from calving to first insemination, days open, paternal and maternal calving ease, paternal and maternal stillbirth. The animal data set contained 2,527 daughter-proven Holstein bulls from Germany that were genotyped with Illumina's BovineSNP50 BeadChip (Illumina Inc., San Diego, CA). For the cLDLA, 41,635 sliding windows of 40 adjacent single nucleotide polymorphisms (SNP) were used. At each window midpoint, a variance component analysis was executed using ASReml. The underlying mixed linear model included random quantitative trait locus (QTL) and polygenic effects. We identified 50 genome-wide significant QTL. The most significant peak was detected for direct calving ease
\end{abstract}

\footnotetext{
Received May 25, 2016.

Accepted November 20, 2016

${ }^{1}$ Current address: Department of Crop and Animal Sciences, Albrecht Daniel Thaer-Institute of Agricultural and Horticultural Sciences, Humboldt University of Berlin, Invalidenstr. 42, 10115 Berlin, Germany.

${ }^{2}$ Current address: Department of Animal Sciences, Division of Functional Breeding, Georg-August-University, Burckhardtweg 2, 37077 Göttingen, Germany.

${ }^{3}$ Corresponding author: Ivica.Medjugorac@gen.vetmed.uni-muen chen.de
}

at 59,179,424 bp on chromosome 18 (BTA18). Next, a mixed-linear model association (MLMA) analysis was conducted. A comparison of the cLDLA and MLMA results with special regard to BTA18 showed that the genome-wide most significant SNP from the MLMA was associated with the same trait and located on the same chromosome at 57,589,121 bp (i.e., about $1.5 \mathrm{Mb}$ apart from the cLDLA peak). The results of 5 different cLDLA and 2 MLMA models, which included the fixed effects of either SNP or haplotypes, suggested that the cLDLA method outperformed the MLMA in accuracy and precision. The haplotype-based cLDLA method allowed for a more precise mapping and the definition of ancestral and derived QTL alleles, both of which are essential for the detection of underlying quantitative trait nucleotides.

Key words: cattle, fertility, calving traits, quantitative trait locus mapping

\section{INTRODUCTION}

Over the last few decades, an association between increasing milk yield and decreasing fertility has been observed in Holstein cattle (Hoekstra et al., 1994; Walsh et al., 2011). In 2013, German Holstein-Friesians reached on average only 2.7 lactations before slaughter; Red Holsteins showed a comparable number (2.8 lactations). In general, about $21.5 \%$ of all dairy cows were slaughtered due to infertility (ADR, 2014). Infertility thus represented the most common reason for culling of dairy cows. Moreover, Dematawena and Berger (1997) estimated costs per cow at around $\$ 380(\sim £ 230$ in 1996) for dystocia grade 5 (out of 5 ), and McGuirk et al. (2007) reported $£ 395(\sim € 568, \$ 825$ in 2007) for serious calving difficulties, both of which require veterinary assistance. However, dystocia not only causes economic costs, but is also a very serious problem in terms of animal welfare. According to Huxley and Whay (2006), dystocia is one of the most painful conditions in cows (pain score 7 out of 10). 
To identify loci with a major effect on fertility and thus find a solution to this serious problem, a lot of research has already been conducted (Kühn et al., 2003; Thomasen et al., 2008; Cole et al., 2009, 2014b; Seidenspinner et al., 2009; Sahana et al., 2011). These studies covered various Holstein subpopulations [German Holsteins: Kühn et al. (2003), Seidenspinner et al. (2009), Cole et al. (2014b); US Holsteins: Cole et al. (2009), Danish Holsteins: Sahana et al. (2011), Thomasen et al. (2008); Swedish Holsteins: Sahana et al. (2011)] and were based on genome-wide microsatellite (Kühn et al., 2003; Thomasen et al., 2008; Seidenspinner et al., 2009) or SNP markers (Cole et al., 2009; Sahana et al., 2011; Cole et al., 2014b). They consistently identified a very prominent QTL for various fertility traits on chromosome 18 (BTA18) in a region roughly located between 50 and $60 \mathrm{Mb}$. However, the underlying mutation has not been identified yet (Cole et al., 2014a,b).

The overall objective of this study was to add new information that will help to resolve the serious fertility problem in Holstein dairy cattle. To reach this aim, a genome-wide SNP-based combined linkage disequilibrium and linkage analysis (cLDLA) as already described in Rothammer et al. (2014) and Kunz et al. (2016) was chosen for QTL mapping. In contrast to most of the previous SNP-based studies that primarily performed genome-wide association analyses and identified only SNP-trait associations (Cole et al., 2009, 2011, 2014b; Sahana et al., 2011; Purfield et al., 2014), this study was optimized to identify haplotype-trait associations. Furthermore, the results of 5 different cLDLA and 2 genome-wide association study (GWAS) models (mixed-linear-model association, MLMA; Yang et al., 2014), which all included the fixed effects of SNP or haplotypes, were compared. We were thus able to draw conclusions regarding the QTL positions and the performance of the 2 mapping methods.

\section{MATERIALS AND METHODS}

\section{Animals and Phenotypes}

This study used 2,527 daughter-proven AI Holstein sires. Mapping of QTL was carried out for the following 10 calving and fertility traits: days from first service to conception of heifers (FSTC-h) and cows (FSTCc), nonreturn rate on d 56 of heifers (NR56-h) and cows, days from calving to first insemination (CTFS), days open (DO), paternal calving ease (pCE) for heifers, maternal calving ease ( $\mathbf{m C E})$ for heifers, paternal stillbirth (pSB) for heifers, and maternal stillbirth (mSB) for heifers. Depending on the authors' preferences, varying synonyms for the same trait are found in the literature. "Calving ease," for example, is also known under the terms "dystocia" or "calving difficulty." Furthermore, "direct" and "indirect" are synonymously used for "paternal" and "maternal." For reasons of clarity, especially when discussing the results of other studies, we used the terms "calving ease," "paternal," and "maternal" regardless of the terminology in the original publications. Pedigree records and EBV were taken from the official breeding value evaluation of daughter-proven bulls, which was performed by Vereinigte Infomationssysteme Tierhaltung (VIT, Verden, Germany) in June 2013. The genotyped sires built a complex pedigree of 239 half-sib families. The number of sons per grandsire ranged from 2 to 95 with an average of 5.6 sons. Three families included more than 50 sons, 9 families had 30 to 49 sons, 68 families had 10 to 29, and 159 families had 2 to 9 sons. Because this study only used already existing data and DNA from previous projects (Thaller, 2011; Medugorac et al., 2012; ZellerAdam, 2013), no specific permission or ethical approval was required. Moreover, original semen samples were collected by approved commercial AI stations as part of their regular reproduction and breeding management program.

\section{Genotyping Data, Quality Control, and Reconstruction of Haplotypes}

The DNA of all animals was genotyped for either 54,001 SNP using version 1 of the BovineSNP50 Genotyping BeadChip (Illumina Inc., San Diego, CA) or for 54,609 SNP using version 2 of this BeadChip. The SNP positions were determined according to the Bos taurus UMD 3.1 reference assembly. For further analysis, all markers that met one of the following criteria were excluded: (1) call rate of less than 95\%, (2) frequent paternity conflicts in animals with confirmed paternity (i.e., SNP showing Mendelian error rates of more than $0.2 \%$ ), (3) unknown position according to the UMD 3.1 reference assembly, (4) markers with heterozygosity below $5 \%$, and (5) all markers located on bovine chromosomes $\mathrm{X}$ or $\mathrm{Y}$ because we concentrated only on autosomes. After this filtering process, 42,215 SNP remained in the marker set.

A hidden Markov model implemented in Beagle 3.0.4 (Browning and Browning, 2009) was used for reconstruction of haplotypes and imputation of missing genotypes. To improve haplotype reconstruction, additional pedigree information and SNP genotypes from previous projects were used. This included additional Holstein animals without appropriate phenotypes that were related to the animals in our mapping population as well as Bos taurus animals of European origin that otherwise had no direct relevance for this study. Overall, a total of 8,154 genotyped animals, which were 
assigned to 3 cohorts (trios, pairs, and unrelated animals) according to the Beagle manual, were used for haplotyping.

\section{Locus Identity by Descent and Diplotype Relationship Matrix}

The Meuwissen and Goddard (2001) procedure for the prediction of identity by descent (IBD) probabilities from marker haplotypes is capable of estimating the IBD between chromosome pairs at any given position. We adopted this method to estimate the local IBD (LocIBD) at the median position in the 40-SNP sliding windows (i.e., the IBD between putative QTL alleles that are located between SNP 20 and 21 in each window). Following the method described in Lee and Van der Werf (2006) for additive genetic relationship matrices $\left(\mathbf{G}_{\mathbf{R M}}\right)$, the LocIBD matrices were converted into locus diplotype relationship matrices (hereafter the $\mathbf{D}_{\mathbf{R M}}$ matrix). A diplotype is here defined as the specific combination of two 40-SNP haplotypes.

\section{Genome-Wide QTL Mapping}

The genome-wide cLDLA was performed by a procedure equivalent to that described by Meuwissen et al. (2002). Linkage information was exploited during the reconstruction of haplotypes based on the available relationships among the genotyped animals, whereas linkage disequilibrium was accounted for by LocIBD estimation. The mixed linear model used for QTL mapping considered random QTL effects based on the $\mathrm{D}_{\mathrm{RM}}$ and 110 principal components (PC) correcting for population stratification and family relationships, i.e., for polygenic effects. These PC of the unified additive relationships matrix among all animals (Powell et al., 2010) were estimated using R (R Core Team, 2013). Only the top PC that needed to remain in the mixed linear model to explain at least $90 \%$ of the genetic variance [determined using the $\mathrm{R}$ package PARAN (Dinno, 2007)] were included in the following model:

$$
\mathbf{y}=\mathbf{X} \boldsymbol{\beta}+\mathrm{Zq}+\mathbf{e},
$$

where $\mathbf{y}=$ vector of 2,527 phenotypes of the investigated trait, $\mathbf{X}$ and $\mathbf{Z}=$ incidence matrices for fixed and random effects, respectively, $\boldsymbol{\beta}=$ vector of fixed effects (including overall mean $\mu$ and the $110 \mathrm{PC}$ ), $\mathbf{q}=$ vector of random additive genetic effects due to the QTL with $\mathbf{q} \sim N\left(0, \mathbf{D}_{\mathbf{R M p}} \sigma_{q}^{2}\right)$, where $\mathbf{D}_{\mathbf{R M p}}$ is the diplotype relationship matrix at the location $\mathrm{p}(\mathrm{p}=1$ to 41,635 , i.e., the number of investigated positions) of the putative QTL, $\mathbf{e}=$ vector of random residual effects with $\mathbf{e} \sim N\left(0, \mathbf{I} \sigma_{e}^{2}\right)$, where $\mathbf{I}$ is an identity matrix. The random effects $\mathbf{q}$ and $\mathbf{e}$ were assumed to be uncorrelated and normally distributed. The variances $\sigma_{q}^{2}$ and $\sigma_{e}^{2}$ were simultaneously estimated. This basic cLDLA mapping model will hereafter be referred to as model 1.

Variance component analyses for each of the 41,635 positions (10 marker intervals at both the start and the end of each of the 29 autosomes were skipped) and each of the 10 traits were performed using the ASREML package (Gilmour et al., 2009). The logarithms of the likelihood that ASREML estimated for the model with $\left(\log \mathrm{L}_{\mathrm{P}}\right)$ and without QTL effects $\left(\log \mathrm{L}_{0}\right.$; corresponds to null hypothesis) were then used to calculate the likelihood ratio test statistic $\left[\mathbf{L R T}=-2\left(\log \mathrm{L}_{0}-\log \mathrm{L}_{\mathrm{P}}\right)\right]$, which is known to be $\chi^{2}$-distributed with one degree of freedom (Olsen et al., 2004). To keep the false discovery rate low, a significance threshold of LRT $=19.511$, which resembles a $P$-value of less than $10^{-5}$, was chosen. This choice of threshold corresponds to a Bonferronicorrected testing of 1,000 independent hypotheses $(m)$ at a significance level of $\alpha=0.01\left(\alpha / m=10^{-5}\right)$. The 40-SNP windows that were used for estimation of all 41,635 LRT values were moved SNP by SNP along the genome. Because directly neighboring windows only differ by one SNP, the LRT values of neighboring positions contain identical information at 39 out of 40 SNP (i.e., they are not independent of each other). The LRT values distanced by more than $40 \mathrm{SNP}(\sim 2.5 \mathrm{Mb})$ are based on different markers but can still depend on each other due to long haplotypes [i.e., the so-called carryover effect (Meuwissen and Goddard, 2004; Olsen et al., 2004)]. Therefore, the Bonferroni correction applied here considers $1,000(41,635 / 40=1,041)$ independent tests.

The LRT curves were created by plotting LRT values against the corresponding base pairs $\left(\mathbf{L R T _ { \operatorname { m a x } }}\right)$. All local maxima with LRT values $>19.511\left(P<10^{-5}\right)$ were recognized as significant. Confidence intervals for the QTL positions were defined as 2-LOD (log of odds) support intervals surrounding $\mathrm{LRT}_{\max }$ and included all LRT values exceeding $\mathrm{LRT}_{\max }[4 \times \ln (10)]$ (van Ooijen, 1992; Visscher and Goddard, 2004; Kim et al., 2009). The 2-LOD intervals thus correspond to $\mathrm{LRT}_{\max }-2 \mathrm{LOD}$ with $1 \mathrm{LOD}=2 \times \ln (10)=4.605$. To assess if any $\mathrm{LRT}_{\max }$ were mainly caused by the same animals, Spearman's correlations of the animals ranked by diplotype effect were calculated between all peaks on each chromosome. Closely located LRT peaks with a high correlation $\left(\mathrm{r}_{[\mathrm{q} 1, \mathrm{q} 2]}>0.7\right)$ were then assumed to belong to the same QTL.

Summing up, LRT peaks were assigned to QTL according to the following criteria: 
- Only peaks with LRT values >19.511 were considered.

- The LRT peaks for the same trait that were located in the same 2-LOD support interval or in intersecting intervals were assumed to be the same QTL.

- Estimates of LRT statistics at directly neighboring intervals are dependent and reflect the similarity in haplotype architecture. Although 2 LRT values separated by one window length (40 SNP) could partly be due to similar haplotype architecture, they are the result of 2 nonoverlapping variancecovariance analyses. We thus postulated that 2 LRT peaks for the same trait had to be at least one window length (40 SNP) apart to be assigned to independent QTL.

- Peaks for different traits were combined into one QTL when Spearman's correlation of diplotype effects exceeded 0.7, thus indicating strong genetic correlation between the traits at the specific locus (Dancey and Reidy, 2007; Leyer and Wesche, 2007).

For each QTL, a literature search was performed to identify associations that have already been reported for dairy cattle.

\section{MLMA: Genome-Wide Association Study}

To be able to compare the haplotype-based cLDLA results with SNP-based GWAS results, we used the GCTA software and performed a genome-wide association study using the LOCO option (Yang et al., 2014). Since Yang et al. (2014) had shown that in contrast to the $\mathrm{MLM}_{\mathrm{i}}$ approach (candidate marker included), the $\mathrm{MLM}_{\mathrm{e}}$ approach (candidate marker excluded as in GCTA-LOCO) increased power compared with linear regression, the LOCO option was the option of choice. PLINK was used for GCTA-LOCO input file creation (Purcell et al., 2007). This basic association analysis model will hereafter be called MLMA\# 1 , and it was performed on a marker set of 41,787 SNP with MAF $>2.5 \%$. For each SNP, the program estimated a $P$-value representing the magnitude of the SNP-phenotype association. For an easy visual comparison of the GWAS results with the cLDLA results, the negative logarithms of the $P$-values and the LRT values were displayed in combined plots for each chromosome.

\section{Additional cLDLA and MLMA Run on BTA18 for Validation of Results}

To validate the results of the cLDLA in general and the results on BTA18 in particular, we compared 5 different cLDLA and 2 MLMA models. Table 1 gives an overview of the differences between the basic (model 1 and MLMA\#1) and the alternative models (model 2, model 3, model 4, model 5, and MLMA\#2). For paternal calving ease, which is the trait with the genomewide most significant LRT value (LRT $=160.92$, BTA18), we analyzed all haplotypes based on the distribution of diplotype effects. This approach clearly implied covariance between a single discrete haplotype with the most negative diplotype effects (hereafter called Q1) and a large set of various haplotypes excluding Q1 in the remaining part of the diplotype effects distribution (hereafter called q1; see results of model 3). Depending on the presence of the Q1 haplotype, the animals were divided into 3 groups: Q1/Q1, Q1/q1, and q1/q1; q1 represents all possible haplotypes but Q1 $(\mathrm{Q} 1 \notin \mathrm{q} 1)$. These 3 groups were included as fixed effect in model 3 and as artificial SNP in MLMA\#2 (Table $1)$.

The SNP rs109478645 was the most significant SNP for 4 calving traits (body depth, rump width, stature, and strength) in Cole et al. (2009). It was also detected by MLMA\#1 as the most significantly associated SNP with paternal calving ease. We therefore evaluated rs109478645 in 2 models (excluded in model 2 and included as fixed effect in model 4).

Table 1. Description of alternative combined linkage disequilibrium and linkage analysis (cLDLA) and mixed-linear-model association (MLMA) models ${ }^{1}$

\begin{tabular}{|c|c|c|}
\hline Model & Differences from basic model & Results \\
\hline Model 3 & $\begin{array}{l}\text { Vector } \beta \text { included fixed effects of the artificial SNP with genotypes Q1/Q1, Q1/q1, and q1/q1 } \\
\text { corresponding to the most probable QTL allele on BTA18 }\end{array}$ & Figure 4 \\
\hline Model 5 & rs 43072554 at $58,696,066 \mathrm{bp}$ on BTA 18 excluded & Figure 7 \\
\hline MLMA\#2 & $\begin{array}{l}\text { Artificial SNP with genotypes Q1/Q1, Q1/q1, and } \mathrm{q} 1 / \mathrm{q} 1 \text { corresponding to the most probable QTL allele on } \\
\text { BTA18 included. MLMA\#2 is equivalent to cLDLA model } 3 .\end{array}$ & $\begin{array}{l}\text { Results of } \\
\text { MLMA\#2 }\end{array}$ \\
\hline
\end{tabular}

${ }^{1}$ Only the differences to the basic models (model 1 and MLMA\#1) that are described in the main text are given. The Results column points out the most important results of a given model. 
The SNP rs43072554, which was the most significant SNP for paternal stillbirth in Cole et al. (2011), was identical with SNP 20 of the most significant 40-SNP window in the cLDLA for paternal calving ease. Therefore, SNP rs43072554 was excluded in model 5 .

\section{RESULTS}

\section{Genome-Wide QTL Mapping}

In total, 90 significant $\left(P<10^{-5}\right)$ LRT peaks were identified for all 10 traits of interest. According to the 4 criteria described in Materials and Methods, these 90 LRT peaks represent 50 QTL (Table 2). The most significant QTL of all chromosomes and traits is located on BTA18 and affects pCE and pSB. Figure 1 shows that although significant associations were found for all traits, the number of peaks varied considerably from 4 (FSTC-h) to 14 (pCE). Table 2 shows the distribution of the significant LRT peaks per trait and chromosome and the final number of QTL per chromosome. Table 3 offers more detailed information (trait composition, chromosome, physical position, and LRT values) on the 50 significant QTL.

A literature search showed that in many cases the used Bos taurus reference genome had meanwhile become obsolete. Therefore, time-consuming procedures were necessary to check the actual UMD 3.1 marker positions in ensembl (cow release 77, October 2014, accessed November 17-18, 2014) or Arkdb (accessed November $17-18,2014)$. In cases where the actual UMD3.1 marker positions were not given, marker sequences were blasted using ensembl. To facilitate similar comparisons for future authors, Supplemental Table S1 (https://doi. org/10.3168/jds.2016-11506) lists all QTL that have been reported for dairy cattle at comparable physical positions and for related traits.

\section{Major Results on BTA18: Results of Model 1}

The genome-wide most significant QTL is located on BTA18 at a position close to what has already been reported by various authors and affects pCE and pSB. Quantitative trait loci with a major effect on fertility traits on BTA18 that were found in this or previous studies are listed in Table 3 and Supplemental Table S1 (https://doi.org/10.3168/jds.2016-11506). The here applied design and criteria suggested 7 different QTL on BTA18. The first QTL (18.1) was mapped between 44,543,348 and 46,396,728 bp and affects CTFS. The second QTL (18.2) between 52,035,136 and 53,042,160 bp affects mCE. The third QTL (18.3) between 54,040,400 and 54,481,864 bp was mapped for mSB. The fourth and most significant QTL (18.4) was

Table 2. Summary of combined linkage disequilibrium and linkage analysis (cLDLA) results (model 1$)^{1}$

\begin{tabular}{|c|c|c|c|c|c|c|c|c|c|c|c|c|}
\hline \multirow[b]{2}{*}{ Chr } & \multicolumn{10}{|c|}{ Trait $^{2}$} & \multirow[b]{2}{*}{$\mathrm{nLRT}_{\max }$} & \multirow[b]{2}{*}{ nQTI } \\
\hline & CTFS & DO & FSTC-h & NR56-h & FSTC-c & NR56-c & $\mathrm{mCE}$ & $\mathrm{mSB}$ & $\mathrm{pCE}$ & $\mathrm{pSB}$ & & \\
\hline 4 & 2 & 1 & - & - & 2 & 4 & - & - & - & - & 9 & 4 \\
\hline 5 & 2 & 1 & - & - & - & - & - & - & 3 & 3 & 9 & 4 \\
\hline 6 & 1 & 3 & - & - & - & - & - & 3 & - & - & 7 & 4 \\
\hline 7 & - & - & - & - & - & - & - & - & 4 & 1 & 5 & 1 \\
\hline 11 & - & - & - & 3 & 1 & - & 1 & 2 & - & - & 7 & 6 \\
\hline 12 & 1 & - & - & - & - & - & 1 & & - & - & 2 & 2 \\
\hline 14 & - & - & 2 & - & 1 & - & - & - & - & - & 3 & 2 \\
\hline 18 & 1 & 1 & - & - & 1 & - & 2 & 1 & 6 & 4 & 16 & 7 \\
\hline 19 & - & - & - & 2 & - & - & - & - & 1 & - & 3 & 2 \\
\hline 21 & 1 & - & - & - & 2 & - & - & - & - & - & 3 & 1 \\
\hline 22 & - & - & - & - & 1 & - & - & - & - & - & 1 & 2 \\
\hline Sum & 11 & 12 & 4 & 7 & 12 & 6 & 9 & 7 & 14 & 8 & 90 & 50 \\
\hline
\end{tabular}

${ }^{1}$ Number of significant QTL with likelihood ratio test statistic (LRT) values >19.511 per trait and chromosome (Chr) as well as the sum of distinct significant $\mathrm{LRT}_{\max }\left(\mathrm{nLRT}_{\max }\right)$ and QTL (nQTL) are shown.

${ }^{2}$ Days from first service to conception of heifers (FSTC-h) and cows (FSTC-c), nonreturn rate on d 56 of heifers (NR56-h) and cows (NR56-c), days from calving to first insemination (CTFS), days open (DO), paternal (direct) calving ease (pCE), maternal (indirect) calving ease (mCE), paternal stillbirth (pSB), and maternal stillbirth (mSB). 


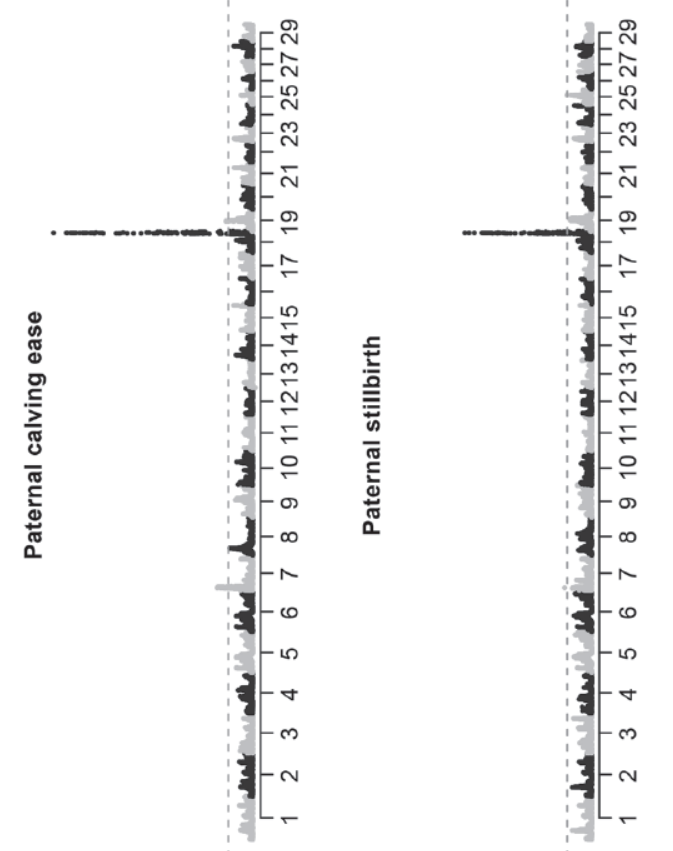

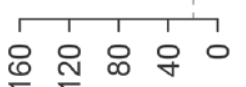
1 เา

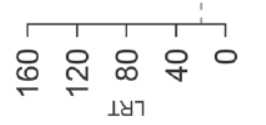

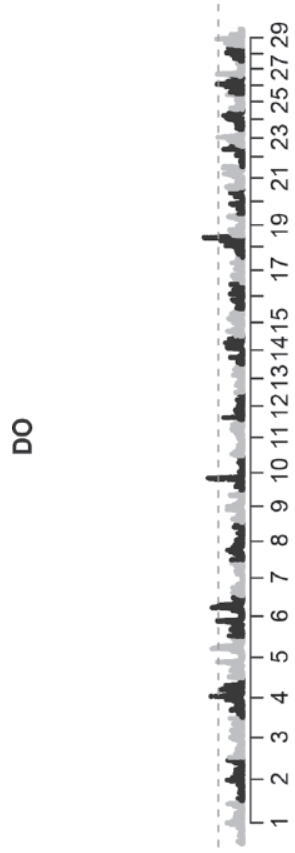

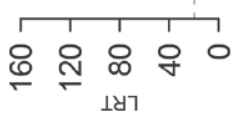

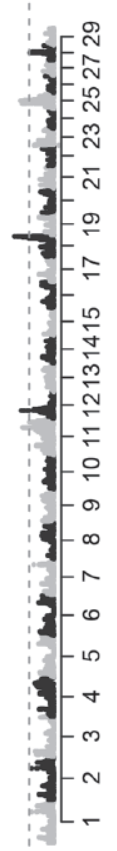

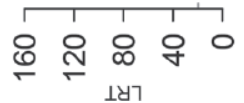
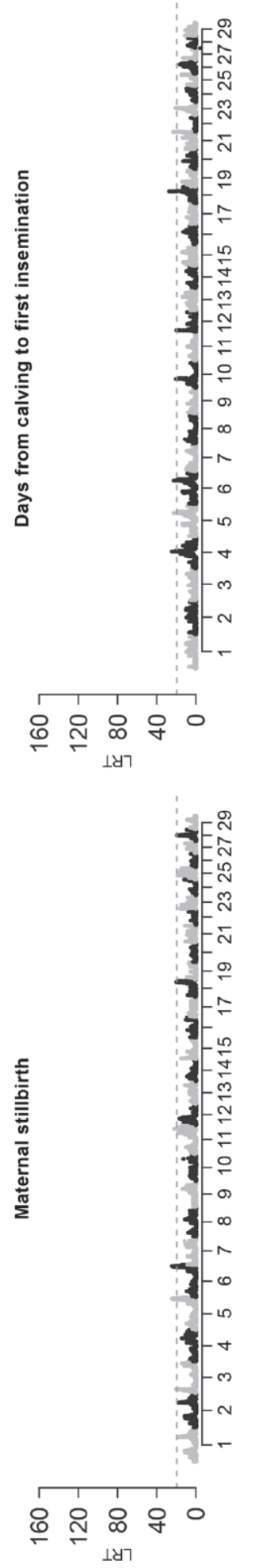
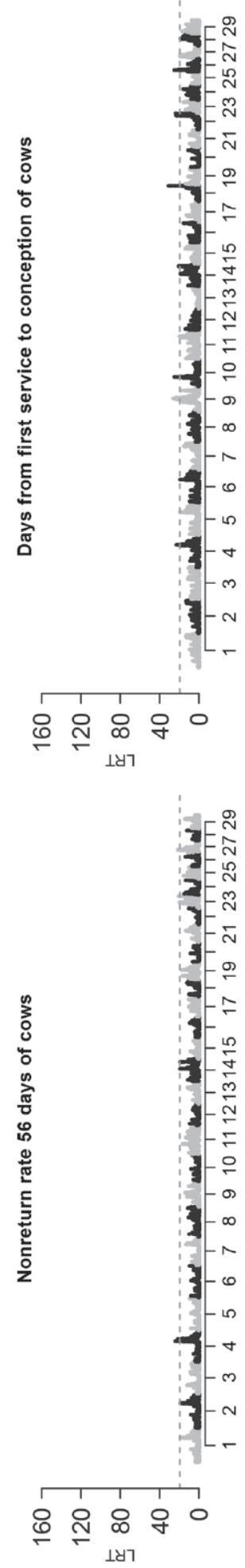
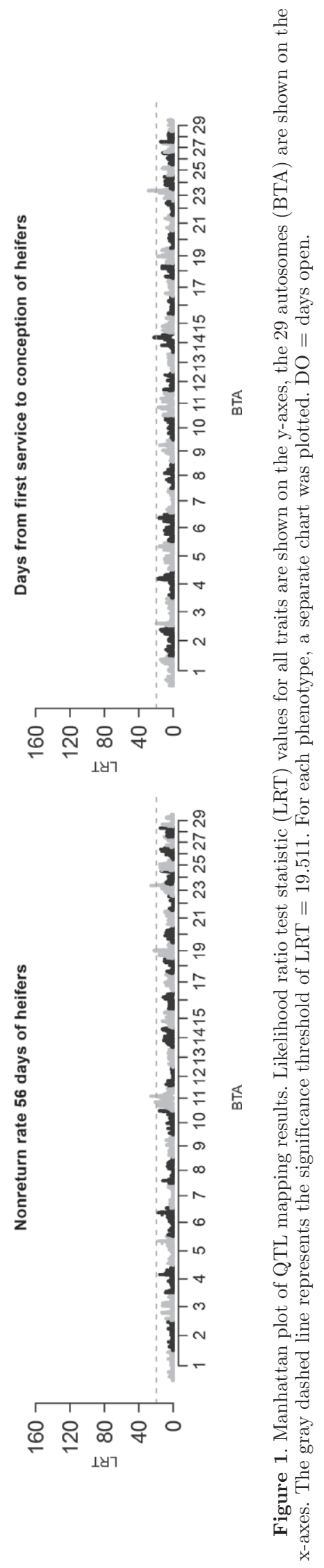
identified for pCE and pSB and mapped to an interval between 55,282,968 and 60,119,636 bp. The fifth QTL (18.5) between 57,206,512 and 59,732,548 bp affects DO and FSTC-c and the sixth QTL (18.6) between $57,959,312$ and $60,119,636$ bp affects mCE. The seventh QTL (18.7) between 62,624,960 and 64,521,568 bp was mapped for $\mathrm{pCE}$ and $\mathrm{pSB}$.

Table 4 presents heritabilities and genome-wide genetic correlations that were provided by VIT for the 10 traits investigated in this study. For reasons of comparison, locus-specific genetic correlations between the same traits at the most significant position that are based on diplotype effects are also presented in Table 4 (estimated with Spearman's test of rank correlations). The most important aspect is the highly positive locusspecific genetic correlation between maternal and paternal traits $\left(\mathrm{r}_{[\mathrm{mCE}, \mathrm{pCE}]}, \mathrm{r}_{[\mathrm{mCE}, \mathrm{pSB}]}, \mathrm{r}_{[\mathrm{mSB}, \mathrm{pSB}]}\right)$ compared with the effectively nonexisting genome-wide correlations $\left(\mathrm{r}_{[\mathrm{mCE}, \mathrm{pCE}]}, \mathrm{r}_{[\mathrm{mCE}, \mathrm{pSB}]}, \mathrm{r}_{[\mathrm{mSB}, \mathrm{pSB}]}\right)$. Furthermore, FSTC-h is not associated with maternal and paternal stillbirth and calving ease on a genome-wide level ( $\mathrm{r}_{[\mathrm{FSTC}-\mathrm{h}, \mathrm{pCE}]}$, $\left.\mathrm{r}_{[\text {FSTC-h-mCE] }}, \mathrm{r}_{[\text {FSTC-h,pSB] }}, \mathrm{r}_{[\text {FSTC-h,mSB] }}\right)$ but shows a strong positive correlation at the most significant QTL $\left(\mathrm{r}_{[\mathrm{FSTC}-\mathrm{h}, \mathrm{pCE}]}, \mathrm{r}_{[\mathrm{FSTCh}, \mathrm{mCE}]}, \mathrm{r}_{[\mathrm{FSTC}-\mathrm{h}, \mathrm{pSB}]}, \mathrm{r}_{[\mathrm{FSTC}-\mathrm{h}, \mathrm{mSB}]}\right)$.

\section{Results of Additional cLDLA Models and Methods Applied to BTA18}

Using the cLDLA approach, the genome-wide most significant peak was found for pCE at 59,179,424 bp, which is located between markers rs43072554 and rs42550320. To compare our haplotype-based cLDLA method with a commonly used SNP-based GWAS approach, we additionally conducted a MLMA. MLMA\#1 identified rs109478645 at 57,589,121 bp on BTA18 as the genome-wide most significant SNP for pCE. In this MLMA model, all SNP with a $P$-value below $10^{-5}$ were declared to be significant. In total, MLMA\#1 revealed $27 \mathrm{SNP}$ for pCE, $23 \mathrm{SNP}$ for $\mathrm{pSB}, 7 \mathrm{SNP}$ for mCE, 4 SNP for DO, 3 SNP for CTFS, and 1 SNP for mSB on BTA18. The exact positions of all significant SNP for pCE and pSB and the overlap with cLDLA results are presented in Table 5. Twenty out of the 27 SNP found for $\mathrm{pCE}$ and 18 out of the $23 \mathrm{SNP}$ found for $\mathrm{pSB}$ on BTA18 were located within the confidence interval of a QTL for the same trait.

\section{Results of Model 2 Excluding rs109478645 from $c L D L A$}

For model 2, the most significant SNP detected by MLMA\# 1 was excluded from the analyses, whereas the mixed linear model did not differ from model 1 . As can be seen in Figure 2, both model 1 and model 2 show highly significant LRT values.

\section{Results of Model 3 - Including the Perfectly Associated Haplotype as Fixed Effect}

Analyses of QTL 18.4, which was the most significant QTL on BTA18, revealed a high diversity of haplotypes at the positive tail of the distribution and a low diversity at the negative tail. All 55 animals with the most negative estimated diplotype effects $(<-7.3)$ were homozygous for the same haplotype (Q1) that consisted of 24 SNP from 58,157,353 to 60,978,019 bp. An additional 562 animals with estimated diplotype effects between -7.3 and -2.0 were heterozygous with one copy of Q1 and diverse other haplotypes encompassed by q1. The remaining 1,910 animals with estimated diplotype effects above -2.0 were homozygous or heterozygous for haplotypes different from Q1. These 55 Q1/Q1 homozygotes and the $562 \mathrm{Q} 1 / \mathrm{q} 1$ heterozygotes presented $13.30 \%$ of all haplotypes (672 out of 5,054). Figure 3 presents the frequencies of the Q1 and q1 haplotypes in subsequent bins of estimated diplotype effects and clearly demonstrates that Q1 indeed causes the observed effect in model 1. From the haplotype distribution, it can also be seen that a single haplotype (Q1) represents QTL allele 1 and that the entire spectrum of all other remaining haplotypes represents QTL allele 2. These QTL alleles cause average diplotype effects for pCE of $-8.78( \pm 1.33),-4.12( \pm 2.12)$, and $0.61( \pm 3.79)$ for Q1/Q1, Q1/q1, and q1/q1 animals, respectively. Model 3 considers Q1/Q1, Q1/q1, and q1/q1 as fixed effects in the mixed linear model and demonstrates a perfect correlation between Q1 and the putative QTL from model 1. In contrast to model 2 , the original LRT peak of the most significant trait for BTA18, pCE, disappeared (see Figure 4, LRT: 2.16 in model 3).

All previously significant calving traits lost their significance along the entire region of BTA18, whereas the LRT statistic for CTFS (QTL 18.1), FSTC-c, and DO (QTL 18.5) changed only marginally and remained significant. For the trait DO, the maximum LRT value at $58,232,128$ bp dropped by around 6 units from 30.2 to 24.761 . For FSTC-c, the LRT value at $58,378,336 \mathrm{bp}$ dropped by around 10 units from 30.82 to 20.04 .

\section{Results of Model 4 Including rs109478645 as Fixed Effect in the cLDLA}

In model 4, a fixed effect based on the rs109478645 genotypes was added to the initial mixed linear model. Compared with model 3, 117 animals were classified differently. As can be seen for pCE and pSB in Figure 5 
Table 3. QTL identified by combined linkage disequilibrium and linkage analysis (cLDLA; model 1), associated phenotypes, position, and $\mathrm{LRT}_{\max }$ (peak) with the 2-LOD (log of odds) support intervals and the overall CI for all traits from the lowest $-2 \mathrm{LOD}$ to the highest $+2 \mathrm{LOD}$ are shown ${ }^{1}$

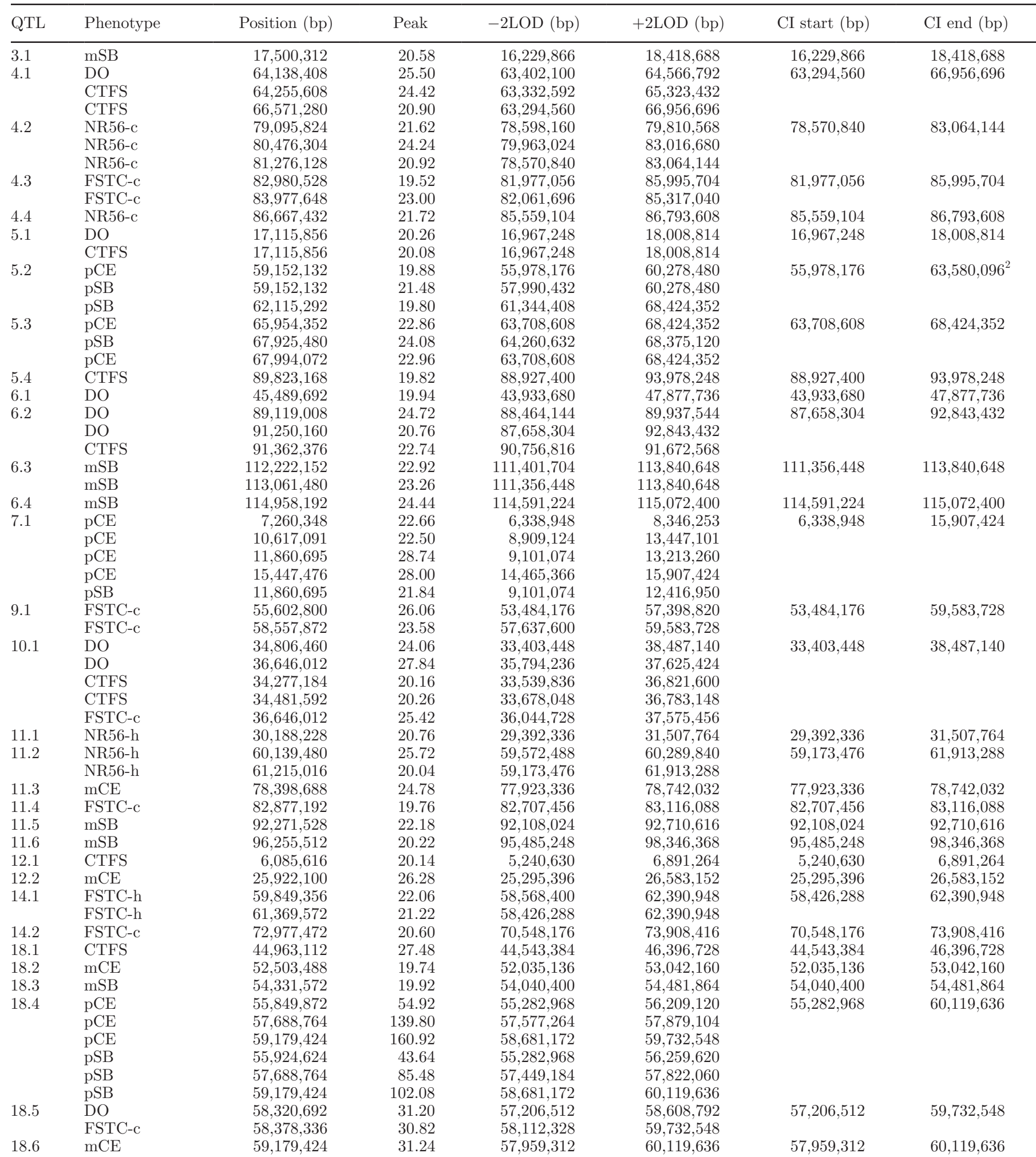


Table 3 (Continued). QTL identified by combined linkage disequilibrium and linkage analysis (cLDLA; model 1), associated phenotypes, position, and $\mathrm{LRT}_{\max }$ (peak) with the 2-LOD (log of odds) support intervals and the overall CI for all traits from the lowest $-2 \mathrm{LOD}$ to the highest $+2 \mathrm{LOD}$ are shown ${ }^{1}$

\begin{tabular}{|c|c|c|c|c|c|c|c|}
\hline QTL & Phenotype & Position (bp) & Peak & $-2 \mathrm{LOD}(\mathrm{bp})$ & $+2 \mathrm{LOD}(\mathrm{bp})$ & CI start (bp) & CI end (bp) \\
\hline \multirow{2}{*}{18.7} & $\mathrm{pCE}$ & $63,143,652$ & 76.62 & $63,108,024$ & $63,390,548$ & & \\
\hline & $\mathrm{pCE}$ & $64,453,288$ & 26.28 & $64,397,252$ & $64,521,568$ & & \\
\hline 19.1 & $\mathrm{pCE}$ & $31,288,920$ & 21.80 & $31,072,674$ & $33,523,396$ & $31,072,674$ & $33,523,396$ \\
\hline \multirow[t]{2}{*}{19.2} & NR56-h & $33,960,888$ & 21.96 & $32,801,004$ & $34,759,236$ & $32,801,004$ & $36,654,424$ \\
\hline & NR56-h & $35,699,856$ & 20.12 & $35,082,160$ & $36,654,424$ & & \\
\hline 22.2 & FSTC-c & $60,042,956$ & 23.56 & $59,473,456$ & $60,094,776$ & $59,473,456$ & $60,094,776$ \\
\hline \multirow[t]{2}{*}{23.1} & DO & $29,704,122$ & 19.54 & $28,638,672$ & $30,068,122$ & $28,362,210$ & $30,068,122$ \\
\hline & CTFS & $29,704,122$ & 20.82 & $28,362,210$ & $30,068,122$ & & \\
\hline 23.2 & FSTC-h & $45,295,144$ & 20.78 & $44,735,156$ & $45,768,732$ & $44,735,156$ & $45,768,732$ \\
\hline \multirow[t]{3}{*}{23.3} & NR56-c & $47,447,552$ & 20.52 & $47,162,736$ & $48,110,124$ & $46,490,824$ & $49,534,016$ \\
\hline & NR56-h & $47,447,552$ & 25.50 & $47,236,176$ & $48,580,288$ & & \\
\hline & NR56-h & $49,045,904$ & 21.28 & $46,490,824$ & $49,534,016$ & & \\
\hline 25.2 & $\mathrm{mCE}$ & $21,377,844$ & 23.98 & $19,446,734$ & $22,863,676$ & & \\
\hline 25.3 & pSB & $25,827,850$ & 19.58 & $25,650,408$ & $27,005,838$ & $25,650,408$ & $27,005,838$ \\
\hline 26.1 & FSTC-c & $7,293,437$ & 25.42 & $7,038,682$ & $8,630,166$ & $7,038,682$ & $8,630,166$ \\
\hline 26.2 & DO & $28,501,052$ & 20.12 & $27,058,344$ & $29,789,824$ & $27,058,344$ & $29,789,824$ \\
\hline 27.1 & DO & $8,815,920$ & 20.18 & $7,699,264$ & $9,295,928$ & $7,699,264$ & $9,295,928$ \\
\hline 27.2 & NR56-c & $12,656,990$ & 21.18 & $11,728,440$ & $12,806,370$ & $11,728,440$ & $12,806,370$ \\
\hline 29.1 & DO & $22,585,872$ & 21.08 & $21,958,846$ & $23,955,240$ & $21,958,846$ & $23,955,240$ \\
\hline
\end{tabular}

${ }^{1}$ Days from first service to conception of heifers (FSTC-h) and cows (FSTC-c), nonreturn rate on d 56 of heifers (NR56-h) and cows (NR56-c), days from calving to first insemination (CTFS), days open (DO), paternal (direct) calving ease (pCE), maternal (indirect) calving ease (mCE), paternal stillbirth $(\mathrm{pSB})$, and maternal stillbirth $(\mathrm{mSB}) . \mathrm{LRT}=$ likelihood ratio test statistic.

${ }^{2}$ This QTL overlaps with the neighboring QTL but does not correlate with any of its peaks. As the exact 2-LOD interval would include this noncorrelated QTL, the lowest LRT value between the 2 QTL (11.26) was chosen instead of the actual 2-LOD value (LRT <10.59).

and Figure 6 for model 4 and model 3, the LRT values declined below the significance threshold $\left(P<10^{-5}\right)$. However, it is obvious that model 3 corrected more effectively than model 4 .

For pCE (Figure 5) at 59,179,424 bp, model 4 still showed a LRT value of 10.979 , whereas in model 3 the LRT value was reduced to 2.16 . A similar result could be shown for pSB, where model 4 was able to correct the LRT value at $59,732,548$ bp to 2.58 and model 3 corrected it to 0.72 (Figure 6).

\section{Results of Model 5 Excluding rs 43072554 from cLDLA}

In model 5, SNP rs43072554, which was identical with SNP 20 of the most significant 40-SNP window, was excluded from the analyses. Compared with model 2 , the values changed significantly and dropped by $\sim 70$ LRT units (from 160.92 to 93.26) for $\mathrm{pCE}$ and also by $\sim 41$ LRT units (from LRT 102.08 to 60.66 ) for pSB at $\mathrm{LRT}_{\max }(59,179,424 \mathrm{bp})$. Figure 7 compares the results of model 2 and model 5 between 40 and $65 \mathrm{Mb}$ on BTA18. Results overlap between 40 and $53 \mathrm{Mb}$ but begin to deviate from each other when the sliding windows reach the point where rs $43072554(58,696,066 \mathrm{bp})$ was excluded.

\section{Results of MLMA\#2: Additional MLMA with a Virtual SNP}

The SNP created for each animal based on the diplotype status at QTL 18.4 (Q1/Q1, Q1/q1, or q1/q1) had an even higher effect $\left(P\right.$-value: $\left.2.87 \times 10^{-42}\right)$ of about 5 decimal places compared with the initially most significant SNP rs109478645 ( $P$-value: $\left.4.07 \times 10^{-37}\right)$.

\section{DISCUSSION}

\section{Discussion of Whole-Genome Results}

With a testing population of 2,527 Holstein bulls, we were able to detect 50 QTL. To verify which of 
Table 4. Correlations between investigated traits ${ }^{1}$

\begin{tabular}{|c|c|c|c|c|c|c|c|c|c|c|}
\hline $\mathrm{VIT} / \mathrm{LRT}_{\max }$ & NR56-h & NR56-c & FSTC-h & CTFS & FSTC-c & $\mathrm{DO}$ & pCE-h & mCE-h & pSB-h & mSB-h \\
\hline NR56-c & 0.70 & $1.5 \%$ & 0.75 & 0.40 & 0.76 & 0.62 & 0.50 & 0.57 & 0.57 & 0.57 \\
\hline FSTC-h & 0.71 & 0.49 & $1.4 \%$ & 0.40 & 0.71 & 0.58 & 0.60 & 0.62 & 0.77 & 0.77 \\
\hline FSTC-c & 0.42 & 0.6 & 0.64 & 0.44 & $1.0 \%$ & 0.93 & 0.58 & 0.53 & 0.64 & 0.64 \\
\hline DO & 0.20 & 0.21 & 0.49 & 0.85 & 0.84 & $2.6 \%$ & 0.55 & 0.46 & 0.54 & 0.54 \\
\hline pCE-h & 0.11 & 0.12 & 0.09 & 0.19 & 0.19 & 0.22 & $4.8 \%$ & 0.66 & 0.87 & 0.63 \\
\hline mSB-h & 0.14 & 0.19 & 0.20 & 0.06 & 0.29 & 0.21 & 0.05 & 0.71 & 0.05 & $5.4 \%$ \\
\hline
\end{tabular}

${ }^{1}$ Above the diagonal, Spearman's rank correlations between the traits at 59,179,424 bp $\left(\mathrm{LRT}_{\max }\right)$ are reported. LRT $=$ likelihood ratio test statistic. The diagonal contains heritabilities (Vereinigte Infomationssysteme Tierhaltung, Verden, Germany; VIT), whereas the genome-wide correlations provided by VIT are shown under the diagonal. Nonreturn rate for $56 \mathrm{~d}$ (NR56) and days from first service to conception (FSTC) of heifer (-h) and cow (-c), days open (DO), days from calving to first insemination (CTFS), maternal (m) or paternal (p) calving ease (CE) and stillbirth (SB) are shown.

the detected QTL were already known, we searched the literature and available databases (e.g., CattleQTLdb, The Bovine Genome Database). To be able to compare our results with previous results that had been mapped to now obsolete genome maps, we transferred all QTL positions to UMD3.1 using ensembl and Arkdb. The UMD3.1 positions of all previous QTL that were mapped to the same region as the QTL in our study are given in Supplemental Table S1 (https://doi. org/10.3168/jds.2016-11506).

In total, 6 out of the 50 QTL from this study have been published recently for the same traits (Supplemental Table S1; https://doi.org/10.3168/jds.2016-11506). Therefore, we were able to map 44 new QTL that, based on the literature and databases searches, have not been described for Holstein before. Our discussion

Table 5. Mixed-linear-model association (MLMA) analysis results for paternal calving ease (pCE) and stillbirth (pSB) on BTA18 ${ }^{1}$

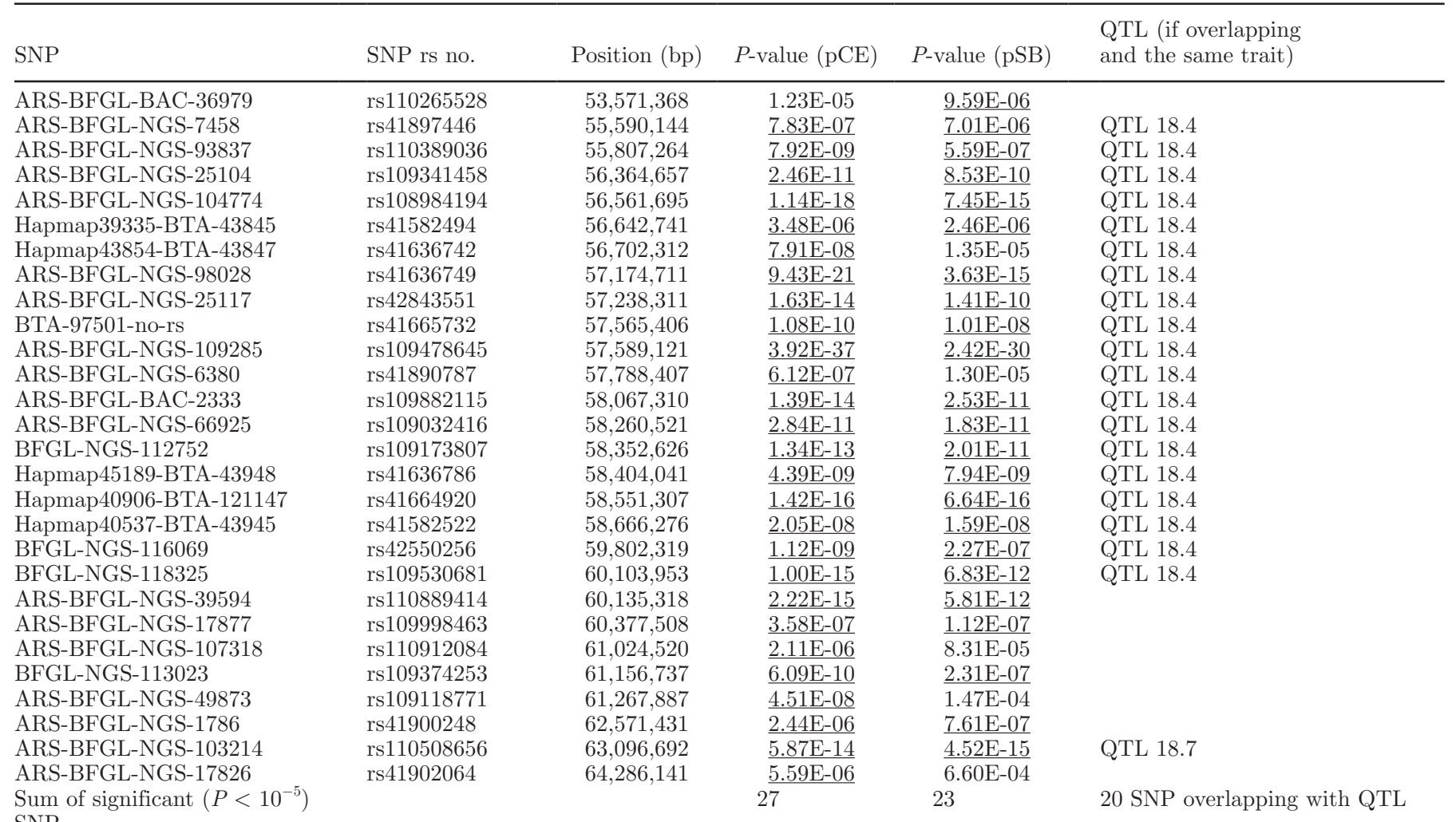

\footnotetext{
${ }^{1}$ All significant SNP $\left(P<10^{-5}\right)$ of MLMA\#1 are underlined. In cases where the SNP is located within the CI of a QTL, the overlapping QTL
}

$\mathrm{SNP}$ is listed in the right column. 
BTA18

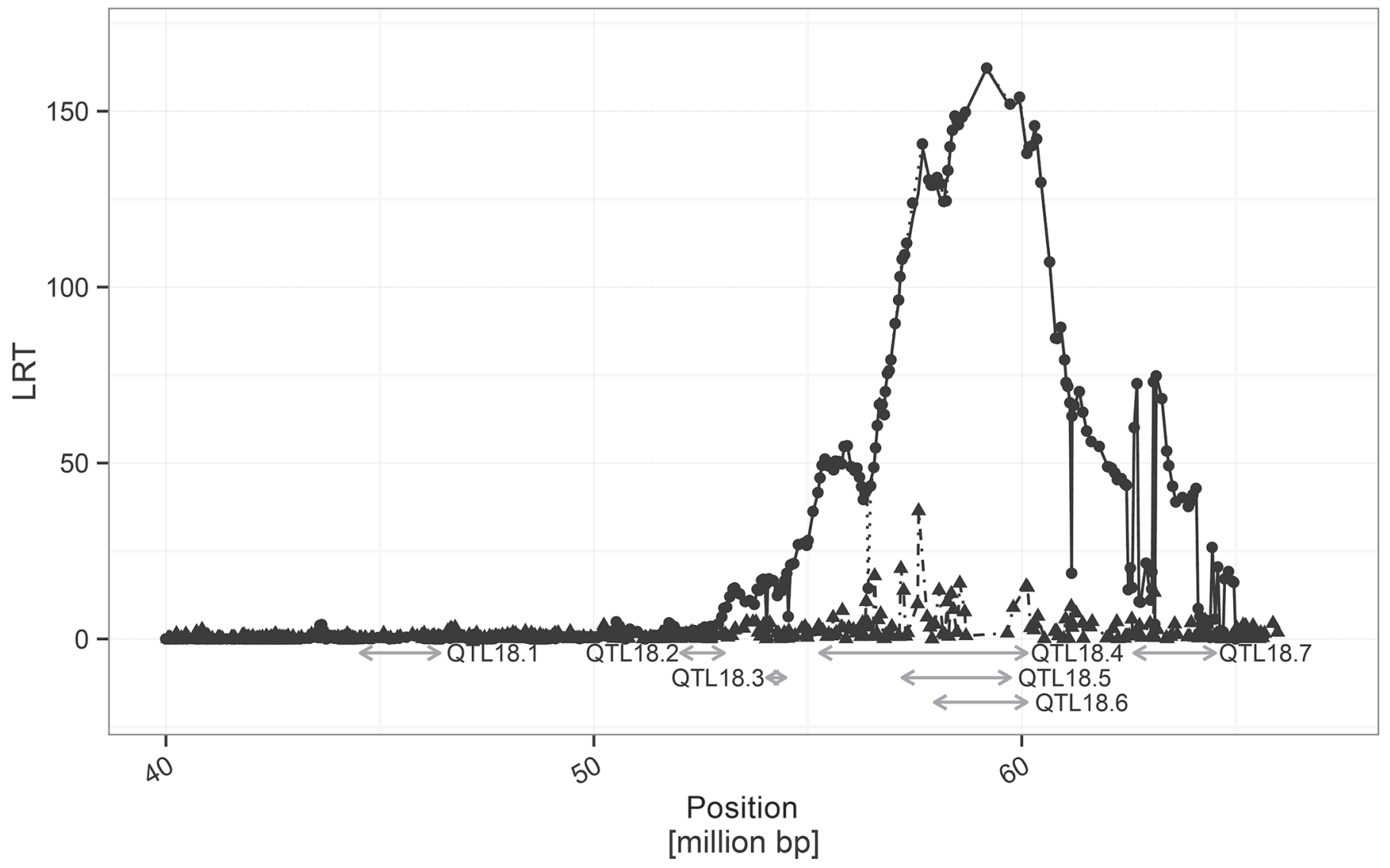

Figure 2. Comparison of the results for paternal calving ease in mixed linear models 1 and 2 and in the mixed-linear-model association analysis (MLMA) \#1. Model 1 (solid line) covers all SNP markers used. In model 2 (dotted line with circles), rs109478645, which is the genomewide most significant SNP in MLMA\#1, is excluded. Due to the very similar likelihood ratio test statistic (LRT) values of model 1 and model 2 , both curves overlap for the bigger part of the region. MLMA\#1 [dash-dotted line with triangles, here unit $=-\log (\mathrm{P})]$ shows the $\operatorname{location}$ of the most significant SNP. For positional orientation, QTL 18.1 to 18.7 are indicated below the x-axis. As some of the QTL were found for other traits besides paternal calving ease, this figure does not show a peak at each QTL.

will focus on certain outstanding QTL: some known and also some newly identified QTL for which possible candidate genes were examined.

\section{Examples of Known QTL}

On BTA5, 3 QTL for twinning that overlapped with QTL 5.2 for pCE and pSB were reported in the literature (Cruickshank et al., 2004: 53,296,546-62,138,446 bp; Kim et al., 2009: 62,125,530-71,561,898 bp; Meuwissen et al., 2002: 62,125,683-62,138,446 bp). As has been known for several years, twin pregnancies come with an increased risk of calving difficulties (Rutledge, 1975) and stillbirth (Hossein-Zadeh et al., 2008). The QTL 5.3 for pCE and pSB also overlapped with 2 QTL mapped for twinning (Kim et al., 2009: 62,125,530-71,561,898 bp; Lien et al., 2000: 66,532,877-71,561,898 bp) and lay next to a third QTL for twinning (Kim et al., 2009:
$69,000,000 \mathrm{bp})$. However, because the data set that is used for estimating the EBV by VIT routinely excludes twin births, the relation between twinning and $\mathrm{pCE}$ and pSB can be excluded as a direct cause of our mapping results. However, QTL 5.2 also overlapped with QTL for body height and birth weight that were both mapped at the same position (Schrooten et al., 2000: $66,532,877-97,454,531)$. The risk factors for dystocia were summarized in a review by Mee (2008) who also pointed out that an excessive birth weight leads to an increased risk. The strong correlation (0.9) between birth weight and calving ease has been known for over 30 yr (Philipsson et al., 1979). It is consequently not surprising that QTL for both traits can be mapped to an identical chromosomal region.

On BTA7, 2 QTL for paternal calving ease and stillbirth (Kühn et al., 2003: 30,308-8,193,566 bp) were found to overlap with QTL 7.1 for pCE and pSB. 


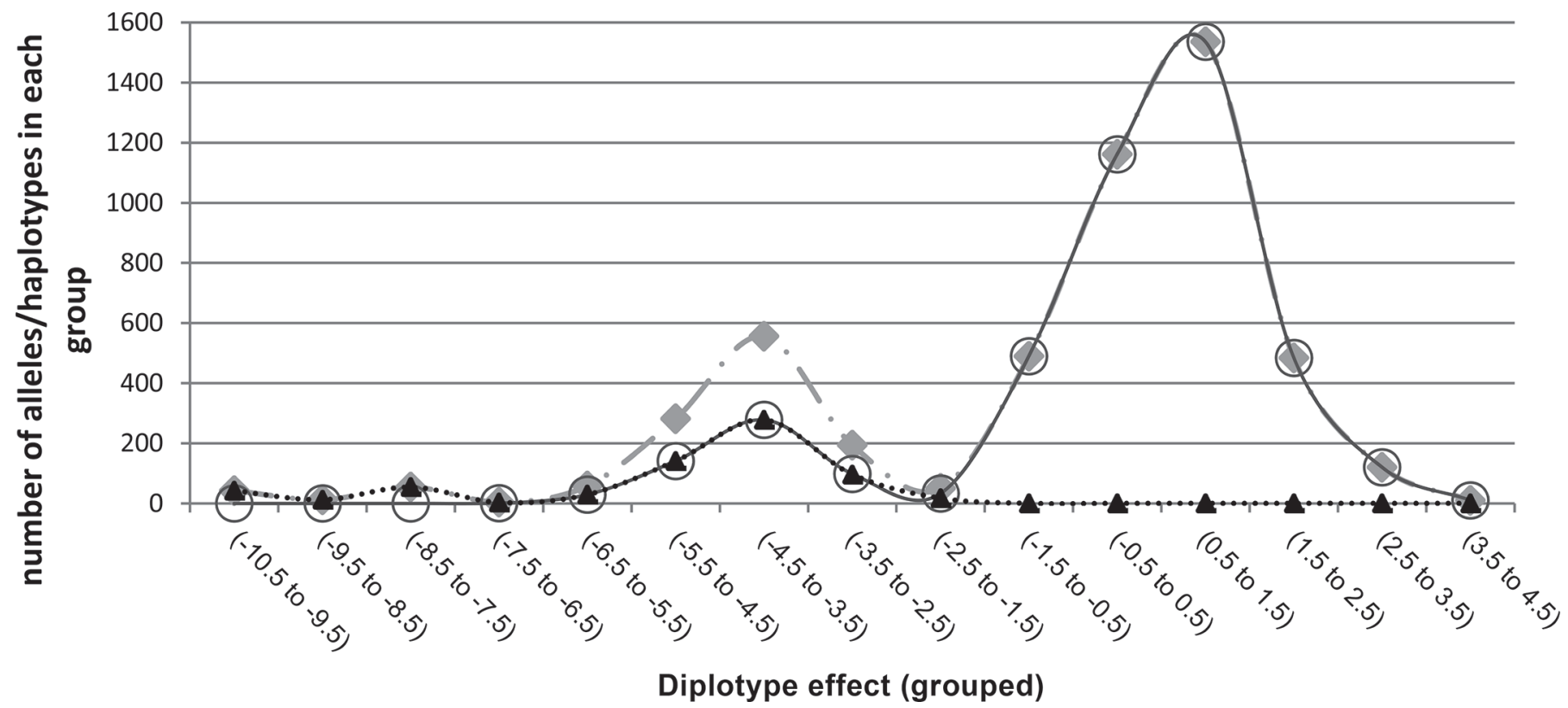

Figure 3. Distribution of the alleles Q1 and q1 in diplotype effect groups (displayed on the x-axis). The dotted black line with triangles shows the sum of the haplotype Q1 alleles in each group of diplotype effects. The dash-dotted gray line with diamonds summarizes all other haplotypes (q1) and the solid black line with circles indicates the total frequency of all haplotypes (Q1 + q1) spread over the classes of diplotype effects.

The literature reported a QTL on BTA19 for paternal calf size, pCE, mCE, and calving index (Sahana et al., 2011: 25,837,047-41,372,598 bp) that overlapped with QTL 19.1 for pCE. Calf size and calving ease have also been subject of recent research (Cole et al., 2009, 2014b). The general relation between calving ease, still-

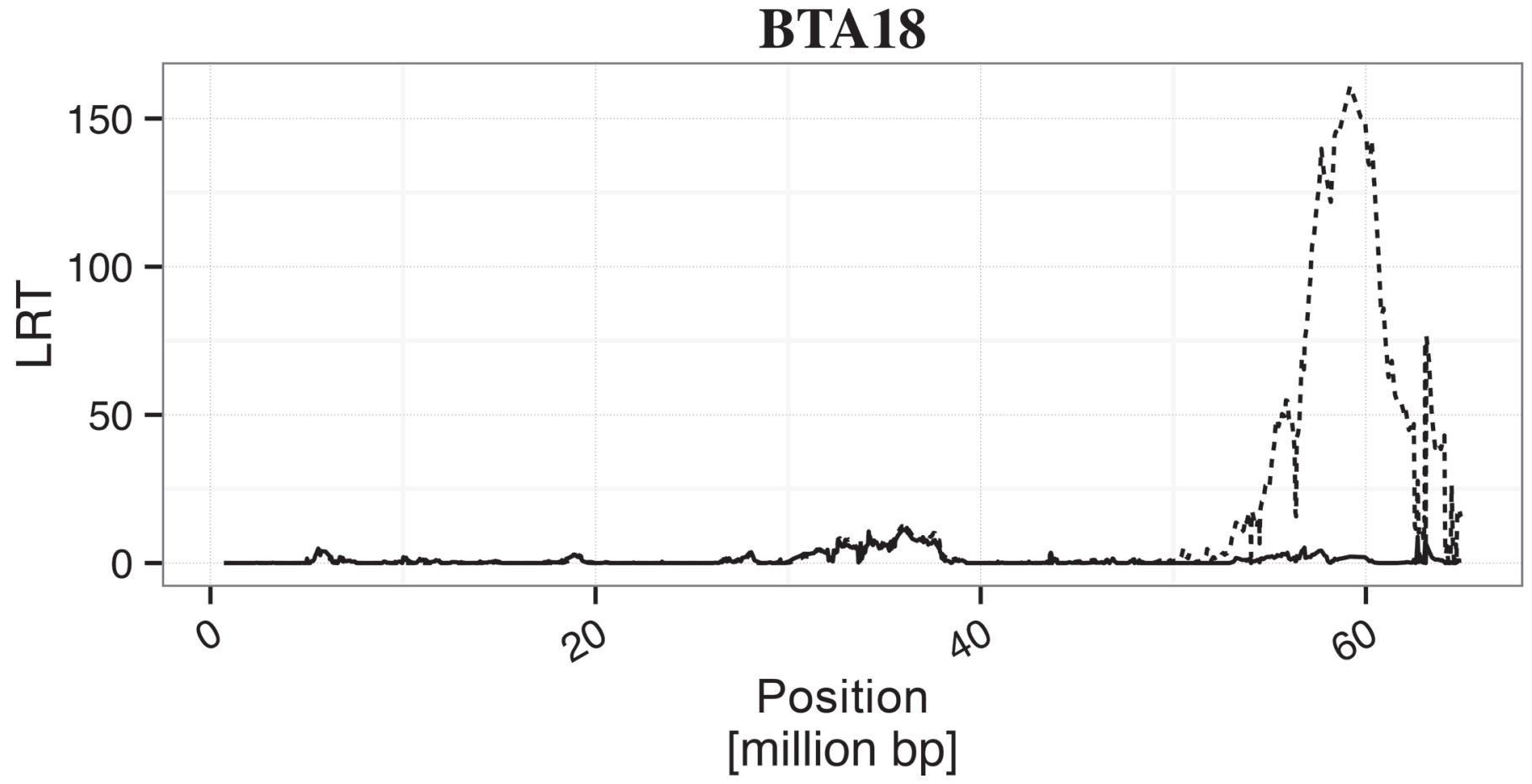

Figure 4. Model 3 for paternal calving ease on BTA18 (solid line), which includes haplotype Q1 as fixed effect, compared with model 1 (dotted line). LRT $=$ likelihood ratio test statistic. 


\section{BTA18}

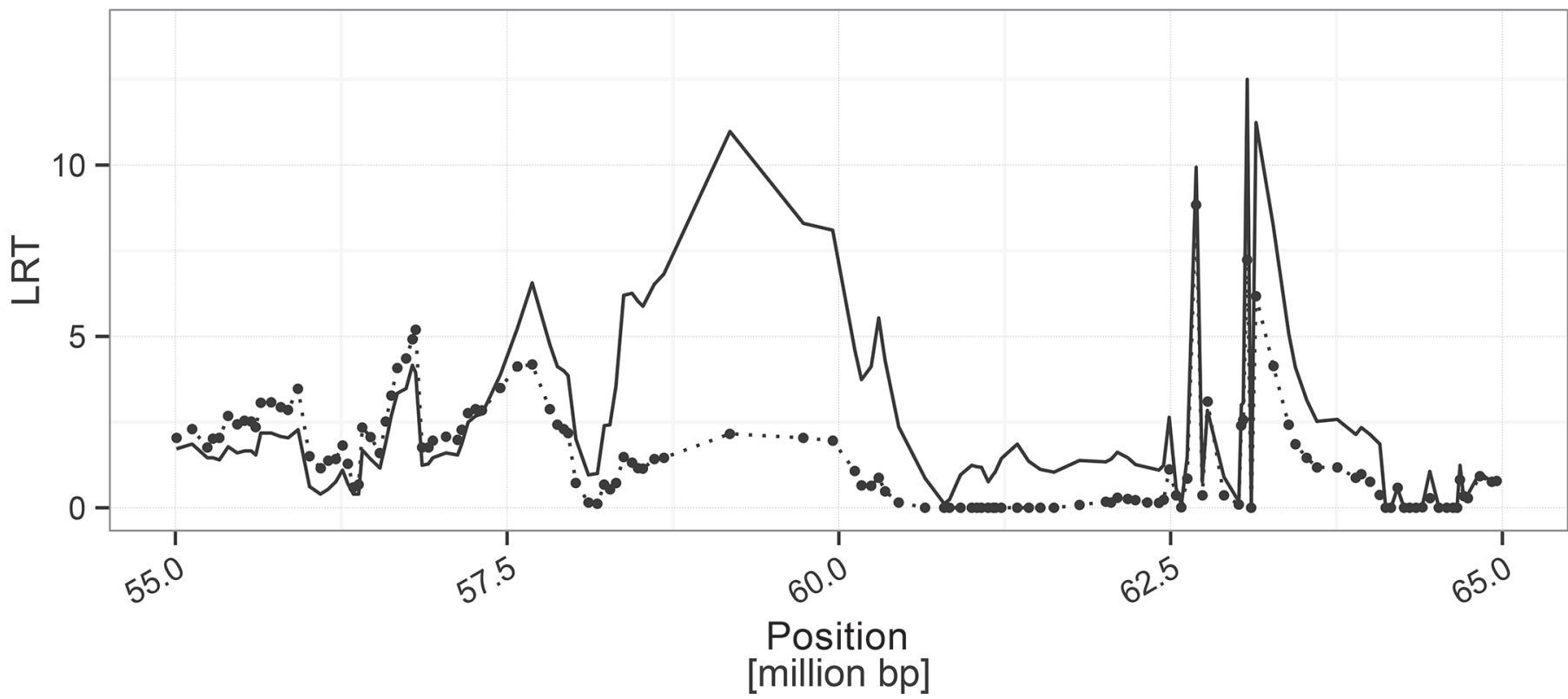

Figure 5. Model 4 (solid line), which includes the most significant mixed-linear-model association analysis (MLMA) SNP rs109478645 $(57,589,121 \mathrm{bp})$ as fixed effect, compared with model 3 (dotted with circles), which includes haplotype Q1 as a fixed effect, for paternal calving ease. $\mathrm{LRT}=$ likelihood ratio test statistic.

BTA18

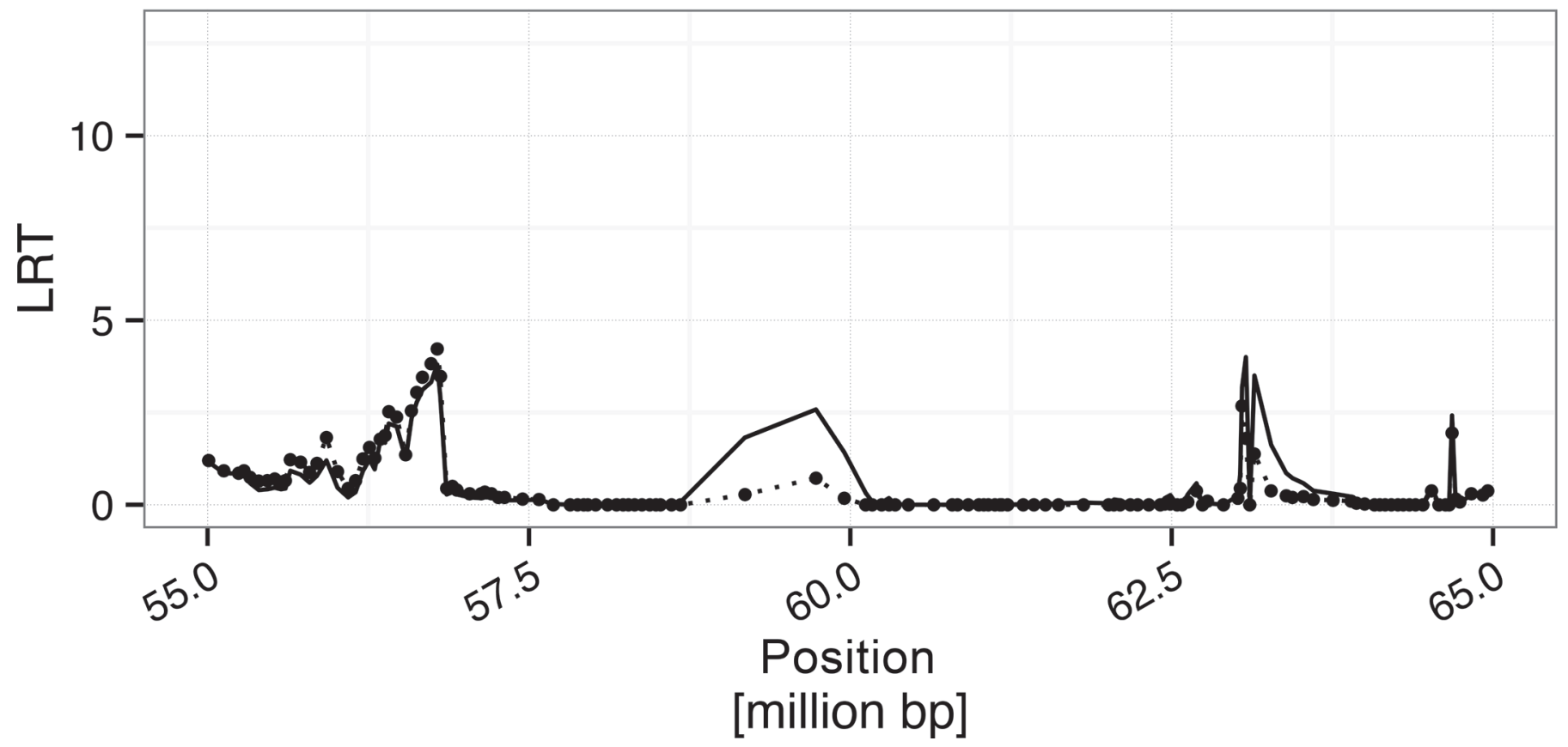

Figure 6. Model 4 (solid line), which includes rs109478645 (57,589,121 bp, the most significant SNP in the mixed-linear-model association analysis) as fixed effect, compared with model 3 (dotted with circles), which includes haplotype Q1 as a fixed effect, for paternal stillbirth. LRT $=$ likelihood ratio test statistic. 


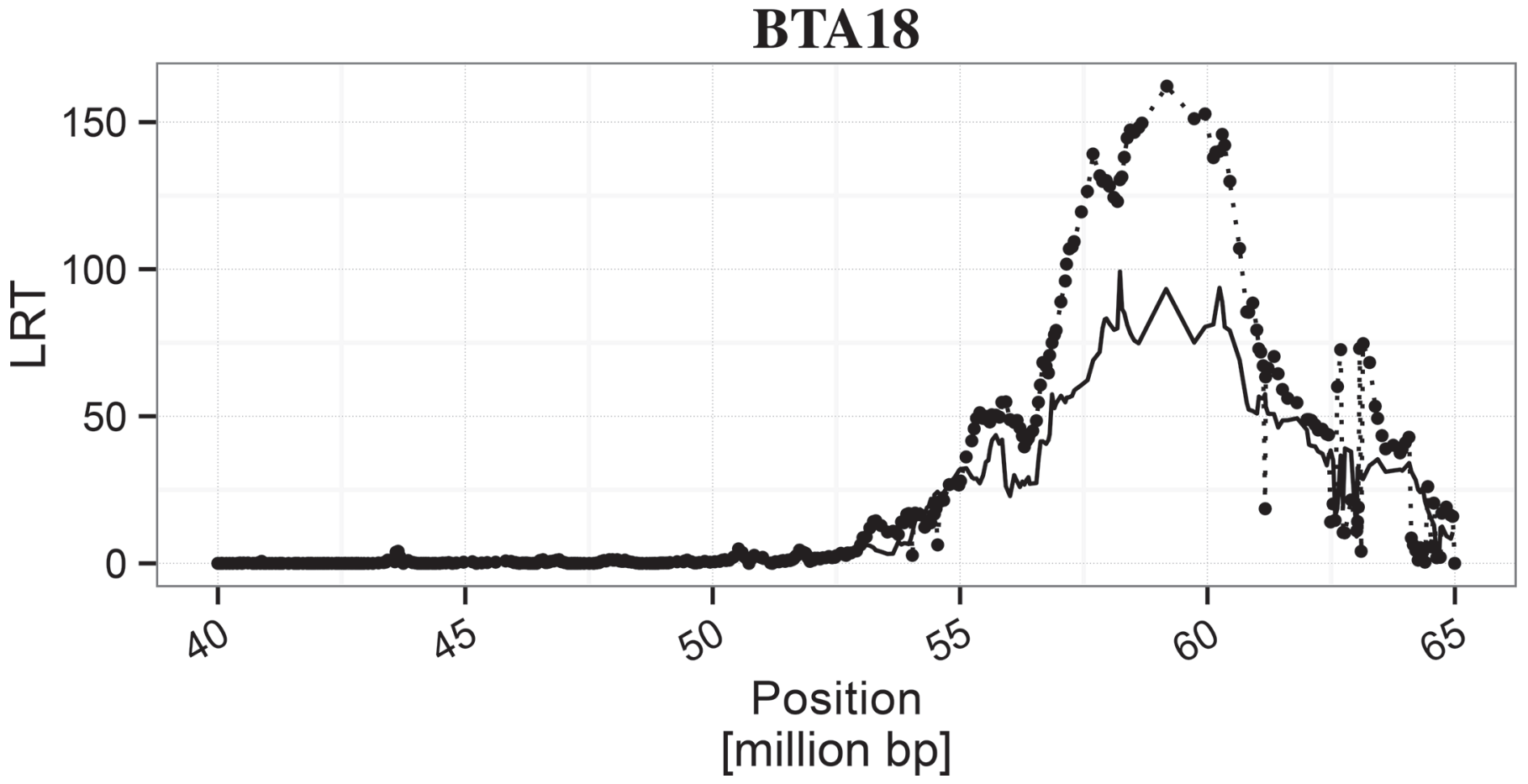

Figure 7. Basic model 1 (dotted with circles) compared with model 5 (solid line), which excludes rs43072554 (58,696,066 bp), for paternal calving ease. LRT $=$ likelihood ratio test statistic.

birth, and calf size has already been mentioned above and according to Menissier and Foulley (1979), the risk of dystocia increases above a range of 42 to $45 \mathrm{~kg}$.

On BTA25, we found a matching QTL for QTL 25.1 that had also been mapped for mCE (Seidenspinner et al., 2009: 6,257,409-12,159,341 bp) in a similar data set (both data sets are highly related and share a high proportion of ancestors). Another match was found for QTL 25.2 for mCE. At this position, a QTL associated with paternal calf size, maternal calf size, and calving index was published previously (Sahana et al., 2011, $16,113,126-22,890,173 \mathrm{bp})$.

\section{New QTL and Candidate Genes}

For all newly identified QTL, LRT $_{\max }$ and the confidence interval were compared with a map of annotated genes in the Ensembl genome browser. Based on the reported function of the genes located in the 2-LOD support intervals, we identified possible candidate genes. We would like to discuss selected QTL for which outstanding candidate genes were found in the OMIM database (www.omim.org).

On BTA7, we were able to identify a gene that might explain QTL 7.1 for pCE and pSB. Relaxin 3 ( $R \boldsymbol{L} \boldsymbol{N}$ 3; $12,768,811-12,770,589 \mathrm{bp}$ ) is located within the 2 -LOD support interval of the QTL $(8,978,524-13,478,592 \mathrm{bp})$.
It acts as "a hypothalamic signal to coordinate food intake, thyroid function and reproductive function" (McGowan et al., 2009). It can be hypothesized that $R L N 3$ influences calving ease by coordination of feed intake. Assuming that $R L N 3$ is expressed prenatally during the transition phase, feed intake could be depressed beyond a regular level. Because the unborn calf has its highest energy requirement shortly before calving, depression of the feed intake is a severe problem for the cow. Furthermore, the calf naturally reduces the feed intake of the dam by taking up space and putting pressure on the rumen and the surrounding guts. As reported by Ingvartsen et al. (1992), a continuous feed depression of $1.5 \%$ per week was observed in a group of heifers between 26 and 3 wk ante partum. Feed intake was reduced from 14 to $9 \mathrm{~kg}$ (depression of around 30\%). These data are consistent with Grummer (1995) who reported a depression of 30 to $35 \%$. Low feed intake during a phase of high energy requirements results in energy deficiency. In this catabolic state, ketone bodies accumulate in the blood stream and the cow reaches a state of clinically manifesting ketosis. For these animals suffering from acute ketosis, calving problems could be a logical consequence.

On BTA11, we were able to identify 2 possible candidate genes for the NR56-h QTL in the OMIM database: the LH receptor ( $L H C G R$ ) and the FSH re- 
ceptor $(F S H R)$ gene. The $L H C G R$ is located between $30,823,435$ and $30,888,003 \mathrm{bp}$ and FSHR between $31,110,744$ and $31,305,197$ bp. The 2-LOD support interval for the NR56-h QTL ranges from 29,431,174 to $31,530,898$ bp (Table 3, QTL 11.1). The FSH induces follicle maturation in the ovaries. It creates a cohort of growing follicles of which one follicle develops into the primary follicle that has the potential to be fertilized by male germ cells. The LH, however, induces the conversion of the ruptured follicle into a corpus luteum, which is a part of the induction and recognition of pregnancy. If heifers have problems either with the LH receptor or with the FSH receptor, the follicle-maturation cascade will not work properly. The animals will not be able to conceive if either no primary follicle is able to mature, or if LH is unable to bind to its receptor to introduce pregnancy.

On BTA14, we were able to identify a candidate gene for a FSTC-h QTL $(58,467,724-62,449,528 \mathrm{bp})$ : the zinc finger protein multitype 2 (ZFPM2) gene. Our QTL 2-LOD support interval (Table 3, QTL 14.1) overlaps with the location of ZFPM2 (60,994,139-61,520,208 bp). The ZFPM2 is co-expressed with GATA-binding protein 4 (GATA4) and thus alternatively named friend of GATA. To prove the function of GATA4 and ZFPM2, Svensson et al. (2000) and Crispino et al. (2001) created GATA4-deficent mice. Tevosian et al. (2000) and Svensson et al. (2000) created mice that were only deficient for ZFPM2. These GATA4- and ZFPM2-deficient mice all died due to cardiac insufficiency around mid-gestation between d 8.5 and 13 (Svensson et al., 2000; Tevosian et al., 2000; Crispino et al., 2001). It can thus be assumed that calves bearing a defect in this gene might also die during gestation. If embryonic death occurs at an early stage, pregnancy might not have been recognized yet, whereas a previous identification of pregnancy might be even doubted in some cases. Consequently, the FSTC timespan might be erroneously increased.

\section{Discussion of Major Results on BTA18}

Using the haplotype identified for QTL 18.4 as a fixed effect (model 3), we observed that besides QTL 18.4 itself, QTL 18.2, 18.3, 18.6, and 18.7 were also affected by QTL18.4 alleles (Q1 and q1). They might thus represent so-called carry-over effects (Meuwissen and Goddard, 2004; Olsen et al., 2004). Therefore, only QTL 18.1 (CTFS) and 18.5 (DO and FSTC-c) remain independent of the strong QTL 18.4, which is primarily associated with $\mathrm{pCE}$ and $\mathrm{pSB}$. These results were confirmed by the estimated Spearman's correlations. The QTL associated with pCE and pSB, which completely disappeared in model 3, showed a high Spearman's correlation of 0.87 between diplotype effects of both traits at that locus. The QTL effects for $\mathrm{mCE}$, which were corrected by QTL alleles of QTL 18.4, showed medium correlations with $\mathrm{pCE}\left(\mathrm{r}_{[\mathrm{mCE}, \mathrm{pCE}]}=0.66\right)$ and $\operatorname{pSB}\left(\mathrm{r}_{[\mathrm{mCE}, \mathrm{pSB}]}=0.67\right)$ at that locus (Table 4). On the other hand, QTL effects for DO and FSTC, which both remained significant in model 3 , showed relatively low correlations $\left(\mathrm{r}_{[\mathrm{DO}, \mathrm{pCE}]}=0.47, \mathrm{r}_{[\mathrm{DO}, \mathrm{pSB}]}=0.38 ; \mathrm{r}_{[\mathrm{FSTC}-\mathrm{c}, \mathrm{pCE}]}\right.$ $\left.=0.55 ; \mathrm{r}_{[\mathrm{FSTC}-\mathrm{c}, \mathrm{pSB}]}=0.52\right)$. Therefore, only the following 3 QTL are discussed in further detail: 18.1, 18.4, and 18.5.

Previous mapping studies with lower resolution showed that QTL 18.1 (CTFS) and 18.5 (DO and FSTCc) both intersected with QTL for paternal calving ease of heifers $(43,245,906-62,106,261 \mathrm{bp})$ and for paternal stillbirth $(43,245,906-62,106,261 \mathrm{bp}$; Seidenspinner et al., 2009). Another QTL (44,853,955-55,860,871 bp) for maternal stillbirth (Thomasen et al., 2008) also overlapped with QTL 18.1. Additionally, QTL 18.5 overlapped with 4 QTL from a study by Sahana et al. (2011) for paternal stillbirth in first and later lactations, birth index, paternal calving ease for first and later lactations, and paternal calf size for first and later lactations, which had also been mapped to an interval between the same markers (rs110389036, rs110889414; $55,807,264-60,135,318 \mathrm{bp})$.

Calving ease is known to influence DO (Thompson et al., 1983; Mangurkar et al., 1984), which is a combination of CTFS and FSTC-c. This is at least partly due to the fact that the bacterial load of the uterus rises with manipulation in the course of calving assistance (Tenhagen et al., 2007; Wagener et al., 2014). The more manipulation takes place, the more the uterus is contaminated with pathogenic bacteria and the more the health status of the cow will be affected, which in turn prolongs the average FSTC timespan. As stated by Tenhagen et al. (2007), cows with severe dystocia conceive later (resulting in an elongated FSTC) and are also more likely to be open by 200 DIM. Due to the close link between these traits, stillbirth also has similar effects. When cows that suffered from stillbirth come into heat the next time, there is an elevated probability that service will not induce conception (Tenhagen et al., 2007), which in turn leads to an elongated DO timespan. Therefore, QTL for maternal stillbirth and CTFS are at least partly connected. However, the comparison of model 1 and model 3 results proves that QTL 18.1 and 18.5 are independent from QTL 18.4 and thus provide another important piece for resolving the BTA18 fertility puzzle in the near future.

In addition to previously described QTL for stillbirth and calving ease in the region of QTL 18.4, the literature search also revealed important correlations between stillbirth and calving ease. In the German and American Holstein population, Cole et al. (2014b) 
estimated BTA18-specific genetic correlations between $\mathrm{pCE}$ and pSB of 0.63 and 0.56 , respectively (VIT predicted $\mathrm{r}=0.73$ genome-wide). We estimated an even higher positive Spearman's correlation (0.87) of diplotype effects for both paternal traits ( $\mathrm{pCE}$ and $\mathrm{pSB}$ ) at the putative QTL 18.4. The fact that the genetic correlations estimated in this study at $59,179,424 \mathrm{bp}$ on BTA18 outperformed even those that were estimated by Cole et al. (2014b) for the whole chromosome is not surprising. The fact that the locus-specific correlation exceeds the genome-wide correlations indicates that on a genome-wide level, more regions have an influence on these traits and the majority of them affect both traits conjointly.

For the same region, Cole et al. (2009) reported a positive correlation $\left(\mathrm{r}_{[\mathrm{pCE}-\mathrm{mCE}]}=0.81\right)$ between paternal and maternal effects for $\mathrm{CE}$ and SB. The positive correlation suggests a QTL with pleiotropic and aligned effects (pointing to the same direction) on both the paternal and maternal traits of $\mathrm{CE}$ and SB. Our results agreed with Cole et al. (2009) because we also detected a peak for $\mathrm{mCE}$ in the same sliding window where the major peaks for $\mathrm{pCE}$ and $\mathrm{pSB}$ were found. Moreover, we also estimated strong positive Spearman's correlations of 0.66 between mCE and pCE diplotype effects at the $\operatorname{LRT}$ peak $\left(59,179,424 \mathrm{bp}, \mathrm{LRT}_{\max }=160.92\right)$ for pCE.

Calving ease and stillbirth are genetically associated because larger calves are at increased risk to be born with more difficulties (Hansen et al., 2004). This is supported by the fact that compared with calves of normal weight, a higher percentage of big calves die during or shortly after calving as a result of the long-lasting and exhausting delivery (Cooke et al., 2009; Roffeis and Krehl, 2011). Genome-wide genetic correlations between maternal and paternal calving traits of zero or even negative values, on the other hand, could be explained by the widely accepted assumption that calves with a high birth weight, which is generally associated with a greater risk of dystocia, grow in larger heifers that usually experience fewer difficulties during delivery (Waurich, 2013; for stillbirth see p. 11, Table 1, and for calving ease see p. 13, Table 2). Quite contrary to the genome-wide expectation, the corresponding locus Spearman's correlation between pSB and $\mathrm{mSB}$ is 0.72 . The discrepancy between the negative genome-wide and the positive locus-specific correlations of paternal with maternal calving traits suggests that this QTL deviates from mainstream effects. The theory that haplotype Q1 might at least partly be responsible for maternal calving traits in this region is thus confirmed. The assumption of a partial effect on maternal traits is further supported by the fact that model 3 reduced the LRT value at QTL 18.2 by about two-thirds. A more detailed investigation of haplotype Q1 should enable the identification of the causal variant(s) for $\mathrm{pCE}$ and $\mathrm{pSB}$ and thus help investigate the residual variance more precisely, for example, by improving mapping results for QTL that segregate independently of 18.4 (QTL 18.1 for CTFS and QTL 18.5 associated with FSTC-c and DO). Uncovering these haplotypes and their causal variants will therefore need additional research. The same applies to improved QTL mapping in other genomic regions and for related traits (e.g., Holmberg and Andersson-Eklund, 2006).

\section{Discussion of the Most Outstanding Candidate Region}

On a genome-wide level, the most outstanding candidate region is the 2-LOD support interval of QTL 18.4 (between 55,282,968 and 60,119,636 bp). Referring to the same region, Cole et al. (2009) are convinced "that there is a QTL on BTA18 that has significant effects on body size, dystocia, longevity, and economic merit. The QTL results in high calf birth weights." They also agree with Meijering (1984) and Mee (2008) that high birth weights, which are associated with a greater risk of dystocia, have a negative effect on fertility and the animals' lifetime economic merit. In 2009, Cole et al. (2009) showed that rs109478645 (BTA18: $57,589,121 \mathrm{bp}$ ) was the most significant SNP for the following traits: body depth, maternal $\mathrm{CE}$, maternal SB, rump width, paternal $\mathrm{CE}$, paternal SB, stature, and strength.

Cole et al. (2011) identified rs43072554 (BTA18: $58,696,066 \mathrm{bp}$ ) as the most significant SNP for pSB, the second most significant SNP for $\mathrm{mCE}$, and the fourth most significant SNP for pCE. This SNP was identical with SNP 20 of the most significant 40-SNP window and was also confirmed as the most significant SNP by our mapping results. However, Cole et al. did not replicate this association in their later studies. In 2014, a GWAS that focused only on birth weight identified rs109882115 (BTA18: 58,067,310 bp) as the most significant SNP. However, the previously detected SNP rs109478645 was confirmed as the third most significant SNP in the generalized linear model and the most significant in the mixed linear model. Furthermore, it was found to be in high linkage disequilibrium with rs109882115. Consequently, Cole et al. (2014b) again declared rs109882115 to be the SNP with the highest association with the effects.

Moreover, Maltecca et al. (2011) found rs109478645 to be the most significant SNP for direct gestation length in the American Holstein population. This SNP is located in an intron of SIGLEC-5 (BTA18: 57,938,695$57,953,490 \mathrm{bp})$. SIGLEC-5 binds to the mouse leptin 
receptor. High expression levels of SIGLEC-5 could result in a deficiency of leptin and thus affect gestation length, which in turn leads to larger fetuses (Cole et al., 2009). Similar connections could also be made for higher birth weights in cattle fetuses as suggested by Cole et al. (2014b). Because big calves are more likely to cause problems during birth, the connections and mutual influences between calving ease, stillbirth, and birth weight are obvious (Mee, 2008; Roffeis and Krehl, 2011; Sahana et al., 2011). A long list of published studies (see Waurich, 2013; for stillbirth see p. 11, Table 1, and for calving ease see p. 13, Table 2) explains the nonexistent to negative genetic correlations between maternal and paternal calving ease and stillbirth. However, QTL 18.4 with $\mathrm{r}_{[\mathrm{pSB}-\mathrm{mSB}]}=0.72, \mathrm{r}_{[\mathrm{pCE}-\mathrm{mCE}]}=0.66$, and $\mathrm{r}_{[\mathrm{pCE}-\mathrm{mSB}]}=0.63$ is fairly different from genome-wide mainstream correlations between these maternal and paternal traits (Table 4). Therefore, other reasons for stillbirth or dystocia besides high birth weight should also be considered. Studies by Burfening et al. (1981), McClintock et al. (2003), Jamrozik et al. (2005), and Van Pelt et al. (2009) described moderate to strong positive genome-wide correlations between maternal calving ease and birth weight. They also indicated the existence of genetic variants with a maternally induced positive effect on prenatal growth at a magnitude that, in turn, is problematic for the cow itself when calving (Waurich, 2013, p. 16).

Cole et al. (2014b) replicated the association of rs109478645 with stillbirth from 2009 and also mapped 4 additional SNP with a large influence on this trait: rs109490807 (at 55,309,510 bp near LIG1), rs41665732 (at 57,565,406 bp near CD33), rs109882115 $(58,067,310 \mathrm{bp}$ near VOM1R1) and BTB-01438985 $(60,258,991 \mathrm{bp}$, located in a large cluster of genes). Additionally, the authors' sequence data suggested that rs109478645 might be misplaced on UMD3.1 (Cole et al., 2014a). Within the range of our haplotype $(58,157,343-60,978,019 \mathrm{bp})$, the genes ZNF432, ZNF614, ZNF350, PPP2R1A, VN1R4, and ZNF877 were identified as positional candidate genes. None of these genes have been linked to calving problems or similar traits so far. PPP2R1A (Shih et al., 2011) and ZNF350, which is also called ZBRK1 (Lin et al., 2013), are known to be associated with breast-ovarian cancer, ovarian clear cell carcinoma, and uterine carcinomas and are thus at least associated with reproductive tissues.

In summary, these results indicate that there has to be a region with major influence on calving in Holstein dairy cows on BTA18. However, despite considerable efforts, a causal variant within the location favored by Cole et al. (2009, 2014b; 57,589,121 bp) has not been identified yet. Consequently, the QTL position should be reassessed. Our haplotype-based design, suggested a slightly different QTL position and rather confirmed the results of Cole et al. from 2011 than those of 2009 and 2014 (Cole et al., 2009, 2011, 2014a).

\section{BTA18: MLMA Compared with cLDLA}

To improve the discussion on the correct QTL position and to compare cLDLA results with a commonly used association analysis, we carried out a genomewide MLMA analysis within the same data set. Similar to Cole et al. (2009), the strongest association in MLMA\#1 was found between pCE and rs109478645. Moreover, SNP rs109478645 was verified to be one of the most significant SNP in the GWAS studies for calving traits of, for example, Sahana et al. (2011), Höglund et al. (2012), and Purfield et al. (2014), and for direct gestation length, which certainly has a strong influence on calving ease, in Maltecca et al. (2011). Similar results close to this position were also obtained by older studies using microsatellite markers [e.g., Kühn et al. (2003), Thomasen et al. (2008), and Seidenspinner et al. (2009)].

All in all, the cLDLA (model 1) results were identical to the main results of MLMA\# 1 . Because we were also able to replicate QTL that had been mapped with other GWAS methods, we are convinced that the cLDLA is a reliable method for QTL mapping. To allow for better comparison of the cLDLA and MLMA mapping results and their soundness, we conducted additional cLDLA (models 2-5) and an additional MLMA (MLMA\#2) analyses. Model 2 formally demonstrated that the exclusion of the most significant SNP (rs109478645) does not have an effect on haplotype-based mapping results. Model 3 included haplotype Q1 as a cofactor and clearly pointed out the presence of large and partly distant carry-over effects of this strong QTL. It was thus demonstrated that appropriate cLDLA modeling is capable of reducing the number of false positives that are caused by distant carry-over effects. In general, the presence of high LD between an unknown underlying quantitative trait nucleotide (QTN), which is embedded in an old (common) haplotype, and some relatively distant SNP could result in a discrepancy between the cLDLA and MLMA results. Moreover, because a single haplotype (Q1) represents QTL allele 1 and the remaining 363 haplotypes represent QTL allele 2 in model 3, it can be suggested that QTL allele 1 is the derived allele (Q1) and QTL allele 2 is ancestral (q1). Furthermore, model 4 met our expectations and verified that the alleles of the most significant SNP in MLMA\#1 (rs109478645) are in LD with the QTN as the modeled fixed effects were able to correct the effect seen for pCE (and other traits) along the entire region. 
Nevertheless, the comparison of model 3 with model 4 suggested a higher association between the putative QTN and Q1 than between the QTN and the alleles of the most significant SNP (the LRT of model 3 is 2.16 , the LRT of model 4 is 10.979 , Figure 5 ). These results were supported by the results of MLMA\#2 that showed a 5 -decimal lower $P$-value $\left(2.87 \times 10^{-42}\right)$ for the modeled Q1-SNP compared with the most significant SNP rs109478645 $\left(4.07 \times 10^{-37}\right)$.

Model 5 pointed out that the SNP rs43072554, which was the genome-wide most significant SNP for pSB, the second significant SNP for $\mathrm{mCE}$ and the fourth significant SNP for pCE (Cole et al., 2011), had a much larger influence in the cLDLA than the SNP rs109478645, which was the genome-wide most significant SNP in Cole et al. (2009, 2014b). As described in the results and seen in Figure 2 (model 2) and Figure 7 (model 5), exclusion of SNP rs43072554 changes the shape of the LRT statistic curve. However, although the LRT statistic is significantly depressed at $\mathrm{LRT}_{\max }$, it still remains clearly significant with a $\mathrm{LRT}_{\max }$ value of $99.16\left(P\right.$-value of $\left.4.59 \times 10^{-22}\right)$.

Because the influence of this QTL region on calving traits has been known for years, a lot of research has already been conducted to identify the causal variant (Kühn et al., 2003; Cole et al., 2009, 2014b; Brand et al., 2010, for direct gestation length: Thomasen et al., 2008; Seidenspinner et al., 2009; Maltecca et al., 2011; Sahana et al., 2011; Purfield et al., 2014). It is thus quite striking that the causal variant still remains unknown. However, as the peaks for pCE in model 1 and MLMA\#1 are about $1.5 \mathrm{Mb}$ apart, it can be hypothesized that a possible failure in identifying the causal variant could be due to examination of the wrong chromosomal segment. Another obstacle in detecting the causal QTN could be the lack of a precise local assembly. Cole et al. (2014a) stated that the sequenced $\sim 8$-kb region downstream of rs109478645 appeared to be misassembled and that the SNP seemed to be misplaced. Consequently, some SNP in the candidate region might be misplaced on UMD 3.1. Our results suggested that the cLDLA approach, which is based on reconstructed haplotypes, is less sensitive to the absence of error-free marker maps and perfectly associated SNP than the GWAS. For reasons of higher accuracy, we therefore prefer haplotype-based methods like the cLDLA over single SNP-based GWAS approaches for QTL mapping. Other methods such as resampled predictive models (e.g., Biffani et al., 2015) or run of homozygosity-based approaches (e.g., Biscarini et al., 2014) also aim to detect more robust association signals than the GWAS. These methods as well as the cLDLA approach should thus be considered as complementary approaches to the standard GWAS in cattle.

\section{CONCLUSIONS}

With a cLDLA-based QTL mapping approach, we were able to detect 50 significant QTL. Our results partly confirmed previous findings and, moreover, identified new QTL. The most significant QTL was found for pCE on BTA18 in a QTL region that has already been mapped by other authors (Kühn et al., 2003; Thomasen et al., 2008; Cole et al., 2009, 2014b; Seidenspinner et al., 2009; Brand et al., 2010; Maltecca et al., 2011; Sahana et al., 2011; Purfield et al., 2014). However, we mapped the most probable position of this QTL to a location about $1.5 \mathrm{Mb}$ away from the published position at rs109478645 (Cole et al., 2009, 2014b). In additional analyses that also included a GWAS using the MLMA method, we showed that this difference was due to the chosen method and that the cLDLA results seem to be superior to those of GWAS. Furthermore, we identified the presumably harmful haplotype. Despite a lot of research that has been done on this QTL so far, the causal variant has still not been successfully identified. It can thus be hypothesized that a false chromosomal segment or some misassembled SNP (or both) in the candidate region were examined in earlier studies. Our results add important new facts to the current knowledge and will contribute to an efficient identification of the causal variant(s). Until then, they enable haplotype-based selection against the most harmful haplotype for pCE.

\section{ACKNOWLEDGMENTS}

The authors acknowledge the German Federal Ministry of Education and Research for funding the FUGATO-plus project GenoTrack (grant no. 0315134A) from which we received genotype data. We thank the colleagues for stimulating discussions and E. Kunz (LMU, Munich, Germany) and S. McLachlan (University of Edinburgh, Edinburgh, UK) for helpful comments on English grammar and syntax that greatly improved the manuscript.

\section{REFERENCES}

ADR. 2014. Rinderproduktion in Deutschland 2013. Arbeitsgemeinschaft Deutscher Rinderzüchter e.V., Bonn, Germany.

Biffani, S., C. Dimauro, N. Macciotta, A. Rossoni, A. Stella, and F. Biscarini. 2015. Predicting haplotype carriers from SNP genotypes in Bos taurus through linear discriminant analysis. Genet. Sel. Evol. 47:4.

Biscarini, F., S. Biffani, E. L. Nicolazzi, N. Morandi, and A. Stella. 2014. Applying runs of homozygosity to the detection of associations between genotype and phenotype in farm animals. Proc. 10th World Congr. Genet. Appl. Livest. Prod., Vancouver, BC, Canada, Comm. 675. Accessed Jan. 9, 2017. https://asas.org/docs/defaultsource/wcgalp-posters/675_paper_9331_manuscript_1670_0.pdf. 
Brand, B., C. Baes, M. Mayer, N. Reinsch, T. Seidenspinner, G. Thaller, and C. Kuhn. 2010. Quantitative trait loci mapping of calving and conformation traits on Bos taurus autosome 18 in the German Holstein population. J. Dairy Sci. 93:1205-1215.

Browning, B. L., and S. R. Browning. 2009. A unified approach to genotype imputation and haplotype-phase inference for large data sets of trios and unrelated individuals. Am. J. Hum. Genet. 84:210-223.

Burfening, P., D. Kress, and R. Friedrich. 1981. Calving ease and growth rate of Simmental-sired calves. III. Direct and maternal effects. J. Anim. Sci. 53:1210-1216.

Cole, J. B., J. L. Hutchinson, D. J. Null, P. M. VanRaden, G. E. Liu, S. G. Schroeder, T. P. Smith, T. S. Sonstegard, C. P. Van Tassell, and D. M. Bickhart. 2014a. The hunt for a functional mutation affecting conformation and calving traits on chromosome 18 in Holstein cattle. Proc. 10th World Congr. Genet. Appl. Livest. Prod., Vancouver, BC, Canada, Comm. 304. Accessed Jan. 9, 2017. https://asas.org/docs/default-source/wcgalp-proceedingsoral/304_paper_10265_manuscript_1272_0.pdf.

Cole, J. B., P. M. VanRaden, J. R. O'Connell, C. P. Van Tassell, T. S. Sonstegard, R. D. Schnabel, J. F. Taylor, and G. R. Wiggans. 2009. Distribution and location of genetic effects for dairy traits. J. Dairy Sci. 92:2931-2946.

Cole, J. B., B. Waurich, M. Wensch-Dorendorf, D. M. Bickhart, and H. H. Swalve. 2014b. A genome-wide association study of calf birth weight in Holstein cattle using single nucleotide polymorphisms and phenotypes predicted from auxiliary traits. J. Dairy Sci. 97:3156-3172.

Cole, J. B., G. Wiggans, L. Ma, T. Sonstegard, T. Lawlor, B. Crooker, C. Van Tassell, J. Yang, S. Wang, L. Matukumalli, and Y. Da. 2011. Genome-wide association analysis of thirty one production, health, reproduction and body conformation traits in contemporary U.S. Holstein cows. BMC Genomics 12:408.

Cooke, R., O. S. Univerrsity, and B. C. Sciences. 2009. Calving School Handbook. Oregon State University, Beef Cattle Sciences, Corvallis.

Crispino, J. D., M. B. Lodish, B. L. Thurberg, S. H. Litovsky, T. Collins, J. D. Molkentin, and S. H. Orkin. 2001. Proper coronary vascular development and heart morphogenesis depend on interaction of GATA-4 with FOG cofactors. Genes Dev. 15:839-844.

Cruickshank, J., M. Dentine, P. Berger, and B. Kirkpatrick. 2004. Evidence for quantitative trait loci affecting twinning rate in North American Holstein cattle. Anim. Genet. 35:206-212.

Dancey, C. P., and J. Reidy. 2007. Statistics Without Maths for Psychology. Pearson Education, Upper Saddle River, NJ.

Dematawena, C., and P. Berger. 1997. Effect of dystocia on yield, fertility, and cow losses and an economic evaluation of dystocia scores for Holsteins. J. Dairy Sci. 80:754-761.

Dinno, A. 2007. paran: Horn's Test of Principal Components/Factors. Accessed Jan. 9, 2017. http://cran.r-project.org/web/packages/ paran/index.html

Gilmour, A. R., B. J. Gogel, B. R. Cullis, and R. Thompson. 2009. ASREML User Guide. Vol. Release 3.0. VSN International Ltd., Hemel Hempstead, UK.

Grummer, R. R. 1995. Impact of changes in organic nutrient metabolism on feeding the transition dairy cow. J. Anim. Sci. 73:28202833.

Hansen, M., M. S. Lund, J. Pedersen, and L. Christensen. 2004. Gestation length in Danish Holsteins has weak genetic associations with stillbirth, calving difficulty, and calf size. Livest. Prod. Sci. 91:23-33.

Hoekstra, J., A. W. van der Lugt, J. H. J. van der Werf, and W. Ouweltjes. 1994. Genetic and phenotypic parameters for milk production and fertility traits in upgraded dairy cattle. Livest. Prod. Sci. 40:225-232

Höglund, J. K., B. Guldbrandtsen, M. S. Lund, and G. Sahana. 2012. Analyzes of genome-wide association follow-up study for calving traits in dairy cattle. BMC Genet. 13:71.

Holmberg, M., and L. Andersson-Eklund. 2006. Quantitative trait loci affecting fertility and calving traits in Swedish dairy cattle. J. Dairy Sci. 89:3664-3671.
Hossein-Zadeh, N. G., A. Nejati-Javaremi, S. R. Miraei-Ashtiani, and H. Kohram. 2008. An Observational analysis of twin births, calf stillbirth, calf sex ratio, and abortion in Iranian Holsteins. J. Dairy Sci. 91:4198-4205.

Huxley, J., and H. Whay. 2006. Current attitudes of cattle practitioners to pain and the use of analgesics in cattle. Vet. Rec. 159:662-668.

Ingvartsen, K. L., H. R. Andersen, and J. Foldager. 1992. Effect of sex and pregnancy on feed intake capacity of growing cattle. Acta Agric. Scand. Anim. Sci. 42:40-46.

Jamrozik, J., J. Fatehi, G. Kistemaker, and L. Schaeffer. 2005. Estimates of genetic parameters for Canadian Holstein female reproduction traits. J. Dairy Sci. 88:2199-2208.

Kim, E.-S., X. Shi, O. Cobanoglu, K. Weigel, P. Berger, and B. Kirkpatrick. 2009. Refined mapping of twinning-rate quantitative trait loci on bovine chromosome 5 and analysis of insulin-like growth factor-1 as a positional candidate gene. J. Anim. Sci. 87:835-843.

Kühn, C., J. Bennewitz, N. Reinsch, N. Xu, H. Thomsen, C. Looft, G. A. Brockmann, M. Schwerin, C. Weimann, S. Hiendleder, G. Erhardt, I. Medjugorac, M. Förster, B. Brenig, F. Reinhardt, R. Reents, I. Russ, G. Averdunk, J. Blumel, and E. Kalm. 2003. Quantitative trait loci mapping of functional traits in the German Holstein cattle population. J. Dairy Sci. 86:360-368.

Kunz, E., S. Rothammer, H. Pausch, H. Schwarzenbacher, F. R. Seefried, K. Matiasek, D. Seichter, I. Russ, R. Fries, and I. Medugorac. 2016. Confirmation of a non-synonymous SNP in PNPLA8 as a candidate causal mutation for Weaver syndrome in Brown Swiss cattle. Genet. Sel. Evol. 48:21.

Lee, S. H., and J. H. J. Van der Werf. 2006. Using dominance relationship coefficients based on linkage disequilibrium and linkage with a general complex pedigree to increase mapping resolution. Genetics 174:1009-1016.

Leyer, I., and K. Wesche. 2007. Multivariate Statistik in der Ökologie. Springer, Berlin, Germany.

Lien, S., A. Karlsen, G. Klemetsdal, D. I. Våge, I. Olsaker, H. Klungland, M. Aasland, B. Heringstad, J. Ruane, and L. Gomez-Raya. 2000. A primary screen of the bovine genome for quantitative trait loci affecting twinning rate. Mamm. Genome 11:877-882.

Lin, L. F., C. F. Li, W. J. Wang, W. M. Yang, D. D. Wang, W. C. Chang, W. H. Lee, and J. M. Wang. 2013. Loss of ZBRK1 contributes to the increase of KAP1 and promotes KAP1-mediated metastasis and invasion in cervical cancer. PLoS One 8:e73033.

Maltecca, C., K. A. Gray, K. A. Weigel, J. P. Cassady, and M. Ashwell. 2011. A genome-wide association study of direct gestation length in US Holstein and Italian Brown populations. Anim. Genet. $42: 585-591$.

Mangurkar, B. R., J. F. Hayes, and J. E. Moxley. 1984. Effects of calving ease-calf survival on production and reproduction in Holsteins. J. Dairy Sci. 67:1496-1509.

McClintock, S., K. Beard, A. Gilmour, and M. Goddard. 2003. Relationships between calving traits in heifers and mature cows in Australia. Interbull Bull. 102-106.

McGowan, B. M., S. A. Stanley, M. A. Ghatei, and S. R. Bloom. 2009. Relaxin-3 and its role in neuroendocrine function. Ann. N. Y. Acad. Sci. 1160:250-255.

McGuirk, B., R. Forsyth, and H. Dobson. 2007. Economic cost of difficult calvings in the United Kingdom dairy herd. Vet. Rec. 161:685-687.

Medugorac, I., D. Seichter, A. Graf, I. Russ, H. Blum, K. H. Göpel, S. Rothammer, M. Förster, and S. Krebs. 2012. Bovine polledness-An autosomal dominant trait with allelic heterogeneity. PLoS One 7:e39477.

Mee, J. 2008. Prevalence and risk factors for dystocia in dairy cattle: A review. Vet. J. 176:93-101.

Meijering, A. 1984. Dystocia and stillbirth in cattle - A review of causes, relations and implications. Livest. Prod. Sci. 11:143-177.

Menissier, F., and J. Foulley. 1979. Present situation of calving problems in the EEC: Incidence of calving difficulties and early calf mortality in beef herds. Pages $30-85$ in Calving Problems and Early Viability of the Calf. Springer, New York, NY. 
Meuwissen, T. H. E., and M. E. Goddard. 2001. Prediction of identity by descent probabilities from marker-haplotypes. Genet. Sel. Evol. 33:605-634.

Meuwissen, T. H. E., and M. E. Goddard. 2004. Mapping multiple QTL using linkage disequilibrium and linkage analysis information and multitrait data. Genet. Sel. Evol. 36:261-279.

Meuwissen, T. H. E., A. Karlsen, S. Lien, I. Olsaker, and M. E. Goddard. 2002. Fine mapping of a quantitative trait locus for twinning rate using combined linkage and linkage disequilibrium mapping. Genetics 161:373-379.

Olsen, H. G., S. Lien, M. Svendsen, H. Nilsen, A. Roseth, M. A. Opsal, and T. H. E. Meuwissen. 2004. Fine mapping of milk production QTL on BTA6 by combined linkage and linkage disequilibrium analysis. J. Dairy Sci. 87:690-698.

Philipsson, J., J. L. Foulley, J. Lederer, T. Liboriussen, and A. Osinga. 1979. Sire evaluation standards and breeding strategies for limiting dystocia and stillbirth. Report of an E.E.C./E.A.A.P. working group. Livest. Prod. Sci. 6:111-127.

Powell, J. E., P. M. Visscher, and M. E. Goddard. 2010. Reconciling the analysis of IBD and IBS in complex trait studies. Nat. Rev. Genet. 11:800-805.

Purcell, S., B. Neale, K. Todd-Brown, L. Thomas, M. A. R. Ferreira, D. Bender, J. Maller, P. Sklar, P. I. W. de Bakker, M. J. Daly, and P. C. Sham. 2007. PLINK: A tool set for whole-genome association and population-based linkage analyses. Am. J. Hum. Genet. 81:559-575.

Purfield, D. C., D. G. Bradley, F. J. Kearney, and D. P. Berry. 2014 Genome-wide association study for calving traits in Holstein-Friesian dairy cattle. Animal 8:224-235.

R Core Team. 2013. R: A Language and Environment for Statistical Computing. R Foundation for Statistical Computing, Vienna, Austria.

Roffeis, M., and I. Krehl. 2011. Ursachen und Folgen von Geburtsproblemen bei Milchkühen. Page 7. Landesamt für Ländliche Entwicklung, Landwirtschaft und Flurneuordnung (LFLF), Brandenburg, Lehr- und Versuchsanstalt für Tierzucht und Tierhaltung E.V. (LVAT), Groß Kreutz, Germany.

Rothammer, S., P. V. Kremer, M. Bernau, I. Fernandez-FigaresIbanez, J. Pfister-Schär, I. Medugorac, and A. M. Scholz. 2014 Genome-wide QTL-mapping of nine body composition and bone mineral density traits in pigs. Genet. Sel. Evol. 46:68.

Rutledge, J. J. 1975. Twinning in cattle. J. Anim. Sci. 40:803-815.

Sahana, G., B. Guldbrandtsen, and M. S. Lund. 2011. Genome-wide association study for calving traits in Danish and Swedish Holstein cattle. J. Dairy Sci. 94:479-486.

Schrooten, C., H. Bovenhuis, W. Coppieters, and J. Van Arendonk. 2000. Whole genome scan to detect quantitative trait loci for conformation and functional traits in dairy cattle. J. Dairy Sci. 83:795-806.

Seidenspinner, T., J. Bennewitz, F. Reinhardt, and G. Thaller. 2009. Need for sharp phenotypes in QTL detection for calving traits in dairy cattle. J. Anim. Breed. Genet. 126:455-462.
Shih, I.-M., P. K. Panuganti, K.-T. Kuo, T.-L. Mao, E. Kuhn, S. Jones, V. E. Velculescu, R. J. Kurman, and T.-L. Wang. 2011. Somatic mutations of PPP2R1A in ovarian and uterine carcinomas. Am. J. Pathol. 178:1442-1447.

Svensson, E. C., G. S. Huggins, H. Lin, C. Clendenin, F. Jiang, R. Tufts, F. B. Dardik, and J. M. Leiden. 2000. A syndrome of tricuspid atresia in mice with a targeted mutation of the gene encoding Fog-2. Nat. Genet. 25:353-356.

Tenhagen, B. A., A. Helmbold, and W. Heuwieser. 2007. Effect of various degrees of dystocia in dairy cattle on calf viability, milk production, fertility and culling. J. Vet. Med. A Physiol. Pathol. Clin. Med. 54:98-102.

Tevosian, S. G., A. E. Deconinck, M. Tanaka, M. Schinke, S. H. Litovsky, S. Izumo, Y. Fujiwara, and S. H. Orkin. 2000. FOG-2, a cofactor for GATA transcription factors, is essential for heart morphogenesis and development of coronary vessels from epicardium. Cell 101:729-739.

Thaller, G. 2011. FUGATO-plus Projekt GENOTRACK. Christian Albrechts Universität zu Kiel, Kiel, Germany.

Thomasen, J. R., B. Guldbrandtsen, P. Sorensen, B. Thomsen, and M. S. Lund. 2008. Quantitative trait loci affecting calving traits in Danish Holstein cattle. J. Dairy Sci. 91:2098-2105.

Thompson, J. R., E. J. Pollak, and C. L. Pelissier. 1983. Interrelationships of parturition problems, production of subsequent lactation, reproduction, and age at first calving. J. Dairy Sci. 66:1119-1127.

Van Pelt, M., G. de Jong, H. Eding, and J. Roelfzema. 2009. Analysis of calving traits with a multitrait animal model with a correlated direct and maternal effect. Interbull Bull. 138.

van Ooijen, J. W. 1992. Accuracy of mapping quantitative trait loci in autogamous species. Theor. Appl. Genet. 84:803-811.

Visscher, P. M., and M. E. Goddard. 2004. Prediction of the confidence interval of quantitative trait loci location. Behav. Genet. 34:477-482.

Wagener, K., I. Prunner, H. Pothmann, M. Ehling-Schulz, and M. Drillich. 2014. Influence of calving assistance on uterine infections with E. coli and T. pyogenes and vaginoscopic findings on day 21 after parturition. 47. Jahrestagung Physiologie und Pathologie der Fortpflanzung, Gießen, Germany.

Walsh, S. W., E. Williams, and A. Evans. 2011. A review of the causes of poor fertility in high milk producing dairy cows. Anim. Reprod. Sci. 123:127-138.

Waurich, B. 2013. Genetische Parameter von Kalbemerkmalen beim Milchrind der Rasse Deutsche Holstein. in Institut für Agrar- und Ernährungswissenschaften der Naturwissenschaftlichen Fakultät III. Martin-Luther-Universität, Halle-Wittenberg, Germany.

Yang, J., N. A. Zaitlen, M. E. Goddard, P. M. Visscher, and A. L. Price. 2014. Advantages and pitfalls in the application of mixedmodel association methods. Nat. Genet. 46:100-106.

Zeller-Adam, R. 2013. Genomweite eQTL-Kartierung ausgewählter Expressionsprofile für das Merkmal Placentaretention in HolsteinKühen. in Fakultät für Tiermedizin. Ludwig-Maximilian-Universität, München, Germany. 